\title{
The Timing of Liquefaction and Its Utility in Liquefaction Hazard Evaluation
}

\author{
S.L. Kramer ${ }^{1}$, S.S. Sideras ${ }^{2}$, M.W. Greenfield ${ }^{3}$
}

\begin{abstract}
The behavior of liquefiable soils, and of soil deposits containing liquefiable soils, can change dramatically upon triggering of liquefaction. This suggests that knowledge of the timing of liquefaction, e.g., whether it occurs early or late in a particular ground motion, would be useful in predicting the potential effects of liquefaction. The relatively recent availability of strong motion records from instruments underlain by liquefiable soils provides a new type of case history - one in which the ground motion intensity at the time of triggering can be identified. The paper reviews procedures for identification of the time of triggering, and shows how that time can be used to judge the relative performance of empirical triggering models. It also introduces a framework for the use of timing information in the development of improved procedures for evaluation of the effects of liquefaction.
\end{abstract}

\subsection{Introduction}

Liquefaction has been a topic of great interest to geotechnical engineers since its devastating effects were first widely recognized some 50 years ago in large earthquakes in Niigata, Japan and Anchorage, Alaska. Great advances have been made in understanding the basic mechanics of liquefaction, and in empirical prediction of its occurrence and effects. Empirical triggering procedures are based on case histories in which liquefaction either did or did not occur as inferred from the presence of absence of surficial evidence such as sand boils, ground cracks, etc. Such binary evidence gives no indication of whether liquefaction was triggered early or late in the causative ground motion. The consequences of liquefaction, however, develop after liquefaction has been triggered, so their severity is expected to be influenced by whether liquefaction was triggered early or late.

The timing of liquefaction has been a missing dimension in liquefaction hazard evaluation. This paper discusses the timing of liquefaction and introduces data and procedures from which it can be determined for select case histories. It then shows how timing information can be used to gain important insights into the accuracy of existing empirical triggering procedures, and how it can be used to make improved predictions of the consequences of liquefaction.

\subsection{Liquefaction}

Empirical prediction of the initiation of liquefaction migrated years ago from a basis rooted in laboratory testing to one that uses observations of the occurrence, and non-occurrence, of liquefaction in the field. The most common of these procedures use a measure of cyclic shear stress amplitude to distinguish between cases of liquefaction and non-liquefaction for soils of 
different densities Because the porewater pressures that produce liquefaction develop incrementally, the cyclic shear stress is modified by a factor intended to account for the number of loading cycles applied to the soil - earthquake magnitude is typically used as a proxy for the number of loading cycles. The results are typically expressed in terms of a factor of safety against liquefaction. Factors of safety less than 1.0 indicate that initiation of liquefaction is expected.

The effects of liquefaction, such as lateral spreading, settlement, and flow sliding, are typically expressed in terms of permanent deformations that are usually estimated by empirical methods. The lack of nearby ground motion records has complicated the development of empirical predictive models; some of the most commonly used (e.g., Youd et al., 2002) characterize loading by means of source parameters such as magnitude and distance rather than ground motion intensity measures. While laboratory element tests have provided important insights into the post-liquefaction behavior of soils, they cannot model the various conditions that exist in real soil deposits, and most often cannot directly replicate all of the large strain conditions that develop in liquefied soils. This situation has retarded the development of analytical procedures for prediction of the effects of liquefaction.

\subsection{Ground Motion Intensity Measures}

Evaluation of both the potential for triggering and the consequences of liquefaction make use of ground motion intensity measures, or $I M \mathrm{~s}$, to describe the characteristics of the ground motions that cause liquefaction. Liquefaction and its consequences are affected by the amplitude, frequency content, and duration of a ground motion, and can also be influenced by the phasing of the motion. Some IMs characterize the amplitude of a motion, and others characterize the frequency content or the duration. While the cyclic stress method, which correlates loading to peak ground acceleration (PGA) in its simplified method implementation, is most commonly used in practice, other intensity measures such as Arias Intensity (Kayen and Mitchell, 1997), modified cumulative absolute velocity (Kramer and Mitchell, 2006), and normalized hysteretic energy (Green et al., 2000) have also been suggested for evaluation of liquefaction potential.

Peak $I M$ s such as peak ground acceleration $(P G A)$, peak ground velocity $(P G V)$, and peak ground displacement $(P G D)$ provide only a measure of the amplitude of the motion, albeit in different frequency ranges. Spectral $I M \mathrm{~s}$ such as Fourier spectral amplitude, spectral acceleration $\left(S_{\mathrm{a}}(T)\right)$ and mean period $\left(T_{\mathrm{m}}\right)$ can indicate which frequencies (or periods) have the strongest amplitudes. Duration-related $I M \mathrm{~s}$ include bracketed duration $\left(T_{\mathrm{B}}\right)$ and significant duration $\left(T_{5-95}\right.$ or $\left.T_{5-75}\right)$. For liquefaction, the number of equivalent loading cycles $\left(N_{\text {eq }}\right)$ and magnitude scaling factor $(M S F)$ can also be used to characterize the effects of ground motion duration. The number of equivalent loading cycles is usually computed based on cycle-counting schemes (Hancock and Bommer, 2004; Liu et al., 2001)) that account for the relative pore pressure generating potential of individual acceleration pulses in a ground motion record. Magnitude scaling factors have been correlated to the number of equivalent loading cycles.

Several intensity measures involve the integration of ground motion characteristics over the duration of shaking - these will be referred to here as evolutionary intensity measures since they evolve over time. Because they are sensitive to amplitude, frequency content, and duration, they are appealing as potential predictors of liquefaction behavior. The best known of evolutionary $I M$ is Arias Intensity $\left(I_{\mathrm{a}}\right)$, which is defined for a single component as 
$I_{a}=\frac{\pi}{2 g} \int[a(t)]^{2} d t$

Another useful evolutionary intensity measure is cumulative absolute velocity $(C A V)$, which is defined as

$$
C A V=\int|a(t)| d t
$$

A composite, liquefaction-specific, evolutionary $I M$ can be constructed by recognizing that the peak ground acceleration increases with time over the course of an earthquake ground motion, at least until the global maximum absolute acceleration is reached after which the $P G A$ no longer increases. The number of equivalent cycles also changes over the course of a ground motion, and will continue to increases until the absolute accelerations drop below a threshold level in the cycle-counting scheme. If the number of cycles is used as the input to a $M S F-N_{\text {eq }}$ correlation (e.g., Liu et al., 2001), a time-varying $M S F$ can be computed. With that information, an evolutionary magnitude-corrected peak ground acceleration $\left(P G A_{\mathrm{M}}\right)$ can be computed, i.e.,

$$
P G A_{M}(t)=\frac{P G A(t)}{M S F(t)}
$$

Note that $P G A_{M}(t)$ can be used to compute the cyclic stress ratio as $\operatorname{CSR}(t)=0.65 P G A_{M}(t) \sigma_{v o} r_{d} / \sigma_{v o}^{\prime}$. Figure 1 illustrates the variation of $I_{\mathrm{a}}, C A V$, and $P G A_{\mathrm{M}}$ with time for the Wildlife ground motion. Note that $I_{\mathrm{a}}$ tends to increase quickly during the strongest portion of the motion (due to the fact that the accelerations are squared), $C A V$ increases at a slower rate in the stronger part of the motion but at a faster rate in the latter part. $P G A_{\mathrm{M}}$ builds up quickly as the global $P G A$ is reached and then increases only very slowly due to a slow increase in the number of equivalent cycles after that time.

\subsection{Evidence of Liquefaction}

The initiation of liquefaction following an earthquake is most commonly indicated by the presence of surficial evidence of high subsurface pore pressure generation, i.e., the presence of sand boils or ground cracks. Sand boils develop when the hydraulic gradients that result from the generation of excess pore pressure cause upward flow of sufficient volume and speed to lift particles of soil and carry them to the ground surface. The liquefiable soils at most sites are overlain by a non-liquefiable crust of some thickness, so the porewater flow will typically find or create cracks or holes through which it can flow to the surface. The formation of sand boils, then, is largely a hydraulic problem. If the non-liquefied crust is too thick, i.e., if the top of the liquefied layer is too deep, sand boils will not form even if liquefaction below the crust does occur. Similarly, if the liquefied layer is too thin, it will not produce enough porewater to cause sand boils to develop. On the other hand, it is possible that a thick, shallow layer of liquefiable soil can develop high pore pressure, say $r_{\mathrm{u}}=80 \%$, and produce sand boils even if the high degree of softening and weakening normally associated with initial liquefaction do not occur. Ishihara (1985) illustrated this concept using empirical observations, primarily based on case history data from the 1976 Tangshan and 1983 Nihonkai earthquakes, in terms of the relative thicknesses of liquefiable and overlying 
non-liquefiable layers, as shown in Figure 2. Thus, although normally a very good indicator of liquefaction, the presence of sand boils is neither a strictly necessary nor sufficient indicator of the occurrence of liquefaction.

\subsection{Effects of Liquefaction on Ground Motions}

The seismic response of a soil profile is strongly affected by the stiffness of the profile, and the stiffness of potentially liquefiable soils is strongly influencd by the effective stress they are under. Since effective stresses in liquefiable soils vary of the course of an earthquake ground motion, their presence should be expected to affect ground motions.

\subsection{Conceptual Effects}

The mechanical behavior of coarse-grained soil has long been known to be closely related to effective stresses. Historically, the greatest attention has been paid to the influence of effective stress on shear strength, but its influence on stiffness is also of critical importance for dynamic response. As pore pressure increases, effective stress decreases. The low-strain shear modulus is typically taken to vary with mean effective stress, $\sigma^{\prime}{ }_{\mathrm{m}}$, as

$$
G_{\max }=G_{o}\left(\frac{\sigma_{m}^{\prime}}{p_{a}}\right)^{n}
$$

where $G_{0}$ is the maximum shear modulus at a mean effective stress of 1 atm and $n$ is an exponent typically found to be approximately 0.5 . Assuming that value, the low-strain shear modulus would vary with pore pressure ratio, $r_{\mathrm{u}}$, as

$$
G_{\max }=G_{o} \sqrt{\frac{\sigma_{m o}^{\prime}\left(1-r_{u}\right)}{p_{a}}}
$$

where $\sigma_{m o}^{\prime}=$ initial mean effective stress, which indicates that the maximum shear modulus is proportional to $\sqrt{1-r_{u}}$. The generation of pore pressure leads to a reduction in effective stress, which, in turn, leads to a reduction in shear modulus of the soil. As a result, the most strongly amplified components of a ground motion shift toward lower frequencies as the motion proceeds. For a simple layer with constant initial shear wave velocity, $V_{\text {so }}$, the initial characteristic site period is given by $T_{\text {so }}=4 H / V_{\text {so. }}$. From Equation (5), the characteristic site period under conditions of increasing pore pressure ratio can be expressed as

$$
T_{s}=\frac{4 H}{V_{s}}=\frac{4 H}{\sqrt{G_{\max } / \rho}}=\frac{4 H}{\sqrt{G_{o}\left(\sigma_{m}^{\prime} / P_{a}\right)^{0.5} / \rho}}=\frac{4 H}{\sqrt{G_{o}\left(\sigma_{m o}^{\prime}\left(1-r_{u}\right) / P_{a}\right)^{0.5} / \rho}}
$$

Thus, the characteristic site period will increase in proportion to $\left(1-r_{\mathrm{u}}\right)^{-0.25}$ as the pore pressure ratio increases. The variation of both characteristic site period and fundamental frequency with pore pressure ratio is illustrated in Figure 3. The effects of pore pressure generation on characteristic site period can be seen to be relatively modest at pore pressure ratios less than about 0.9 but then increase quickly as the pore pressure ratio approaches 1.0 .

The softening associated with initiation of liquefaction can lead to the development of 
significant permanent deformations, even at relatively gently sloping sites. It is notable that permanent deformations, as observed in centrifuge tests and field blasting tests, and in numerical analyses that capture the behavior of liquefiable soils, begin to develop after the initiation of liquefaction. The deformations, therefore, are driven by the post-triggering portion of the ground motion and are not sensitive to the loading that came before liquefaction was triggered.

\subsection{Evolution of Frequency Content in Recorded Ground Motions}

The frequency content of ground motions is affected by different types of waves that arrive at a site. At a particular site, $\mathrm{p}$-waves will arrive first followed by s-waves and then surface waves. P-waves typically oscillate at higher frequencies than s-waves and s-waves oscillate at higher frequencies than surface waves, so there is typically a trend of decreasing frequency with time over the course of a recorded ground motion. These changes in frequency typically occur relatively gradually, particularly compared to the rapid change in characteristic site period associated with initial liquefaction illustrated in Figure 3.

The frequency content of a recorded ground motion is usually expressed in terms of a Fourier amplitude spectrum (FAS). The FAS is computed for an entire motion with the inherent assumption of periodicity. Thus, non-stationary, evolutionary changes in frequency content cannot be represented by a standard FAS. By applying a moving window (in time) to a recorded motion, a short-term Fourier transform (STFT) can be computed on the windowed portion of the motion, and its amplitude plotted vs. both frequency and the time corresponding to the center of the window as an STFT spectrogram. The STFT spectrogram generally provides very good resolution of frequency, but relatively poor resolution of time. A wavelet transform convolves a time history with a wavelet function that is localized in time and centered about a particular frequency. The wavelet can be shifted in time and scaled in frequency by dilating (stretching) or compressing its width. The wavelet transform allows development of a wavelet scalogram that expresses wavelet amplitude as a function of time and central frequency. The scalogram generally provides very good time resolution, but relatively poor frequency resolution. An alternative form of time-frequency analysis is provided by the Stockwell, or S-, transform (Stockwell, 1996). The S-transform uses a moving window of frequency-dependent width to achieve a balance between the resolutions of the STFT and the wavelet transforms - it provides better time resolution than the STFT spectrogram and better frequency resolution than the wavelet scalogram. Figure 4 shows all three time-frequency representations for an artificial signal of variable frequency.

Stockwell spectra for ground motions recorded by instruments underlain by liquefiable soil can show dramatic changes in frequency content over time as the softening of the soil by generated pore pressures affects the frequencies that are amplified and de-amplified by the soil profile. To better illustrate the changing frequency content of a ground motion, variations in amplitude can be removed by normalizing the spectral amplitudes by the peak spectral amplitude at each time step. In some cases, such as the Kawagishi-cho record shown in Figure 5(a), the change in frequency content is so drastic that it can be readily seen in the time history. In other cases, such as the IBR014 record shown in Figure 5(b), the changes in frequency content are more subtle but readily distinguished using the Stockwell spectrum.

\subsection{Identifying the Time of Liquefaction}

A Stockwell spectrum-based procedure (Ozener et al., 2016) has been developed for 
identification of the time at which liquefaction has been initiated in a soil profile beneath a strong motion recording instrument. The procedure makes use of two primary metrics: (1) changes in the mean frequency of the Stockwell power spectrum computed as the norm of the mean frequencies of the two horizontal components of the ground motion, and (2) changes in the ratio of mean horizontal frequency to mean vertical frequency. As a soil profile softens due to pore pressure generation, the mean frequency of the horizontal ground surface motion decreases, and a profile that may have been able to transmit high frequencies to the ground surface prior to initiation of liquefaction may only be able to transmit low frequencies afterwards; in such cases, the mean horizontal frequency can drop quickly at or near the time of initiation. Of course, some component of the changing frequency content of a ground surface motion is due to changes in the frequency content of the motion at the base of the soil profile. Nakamura (1989) proposed a procedure that helped to isolate the fundamental frequency of a soil profile by calculating the ratio of horizontal to vertical ground surface Fourier spectral amplitudes. This procedure assumes that source, path, and Rayleigh wave effects are present in both the horizontal and vertical motions, so the ratio tends to suppress those effects and better reveal site effects in the form of shear wave amplification behavior. The ratio of mean horizontal to mean vertical frequency using Stockwell spectra provides a "moving" view of the peak of the amplification function over time.

Both site frequency metrics correspond to relatively high frequencies prior to the initiation of liquefaction and to lower frequencies thereafter. In order to identify the time of liquefaction, a step function is fit to each frequency metric using a least-squares criterion. The error in the fit can be plotted as a function of the step time to identify the time of liquefaction as corresponding to the time of minimum error. The width of the error function in the vicinity of the minimum also provides an indication of the uncertainty in the time estimate, which varies from case to case and is high for some. The error function is also examined after rotating the recorded motion to 36 azimuthal directions (using a 5-degree increment) to check the consistency of the indicated time of initiation; this step helps confirm that frequency changes are associated with liquefaction (in which case softening occurs in all directions) and not surface waves (which can be directionally dependent).

\subsection{Liquefaction-Influenced Ground Motions}

Over the past 10 years, the authors have collected ground motion recordings from sites underlain by liquefiable soils. A total of 45 such recordings have been assembled and interpreted using the previously described time-frequency analyses. For this paper, a subset of 18 case histories consisting of all cases for which (a) surficial evidence of liquefaction was observed, (b) SPT measurements were available, and (c) triggering times could be determined with good confidence was assembled. Table 1 presents the best-estimate times of initiation for these case histories.

\subsection{Use of Timing Information}

Case histories for which the time of liquefaction can be extracted from ground surface recordings are different than typical, surface evidence-based case histories. Rather than providing binary data points at some distance above or below a liquefaction triggering curve, they can provide data points that should lie on such a curve. They also allow the level of loading imposed by an earthquake to be divided into pre-triggering and post-triggering portions. Given that permanent deformations develop primarily after liquefaction has been triggered, the isolation of post-triggering loading offers some potential for improved 
prediction of the consequences of liquefaction. The use of timing information for improvement of both triggering and consequence prediction is discussed in the following sections.

\subsection{Triggering of Liquefaction}

Knowledge of the time of liquefaction from a recorded ground surface motion allows computation of the values of evolutionary intensity measures at the time liquefaction is triggered. Combining that intensity measure with the penetration resistance of the critical layer for a particular case history allows establishment of a data point that should lie on, rather than simply above or below, a liquefaction resistance curve. Such data points have tremendous value in establishing liquefaction resistance because they provide a much more direct indication of ground motion intensity at the point of initiation than is normally available. Their use requires establishment of the ground motion intensity at the time of triggering and of some measure of soil characteristics that relates to the state of the soil.

\subsection{Identification of CSR at Initiation of Liquefaction}

At first glance, characterization of a case history would simply involve identification and characterization of the critical soil layer, establishment of its corrected penetration resistance, and calculation of the value of the evolutionary $I M$ at the time liquefaction is triggered from the motion recorded at the site. Direct comparison of such "motion-based" data points with classical liquefaction resistance curves based on binary (liquefaction vs. non-liquefaction) "surficial evidence-based" case history data, however, is complicated by three factors. First, the recorded ground motions are influenced by the generation of porewater pressures during shaking, whereas the interpretation of ground motion intensity in conventional procedures is based on ground motions unaffected by pore pressure generation. Second, the penetration resistance that correlates best to the initial occurrence of significant softening is likely to be lower than the average penetration resistance of the soil unit that liquefies. Third, the softening of a soil profile by the generation of excess porewater pressure is a different consequence of liquefaction than the development of surficial evidence of liquefaction. Each of these factors is discussed in the following sections, and first-order, approximate adjustments that allow more consistent comparison of motion-based and surficial evidencebased case history data are presented. Further research on these adjustments is in progress.

\subsubsection{Effects of Pore Pressure on Peak Ground Surface Acceleration}

The stiffness of a liquefiable soil changes as excess pore pressures are generated, so the amplification behavior of a liquefiable soil profile will also change over the duration of a ground motion. As a result, a ground motion recorded at the surface of a soil profile that generates excess pore pressure will be different than the motion that would have been recorded had no pore pressure been generated. The value of the recorded $P G A$ at the time liquefaction occurs, for example, will be different than that which would have occurred with no pore pressure generation.

As part of a study on the effects of liquefaction on ground surface motions, Kramer et al. (2013 - Istanbul paper) performed total and effective stress analyses of nine soil profiles (combinations of three liquefiable layer thicknesses and three soil densities) using three advanced nonlinear effective stress analysis programs - FLAC with the PM4sand 2.0 model (Boulanger and Ziotopoulou, 2012), FLIP with the multi-spring model (Iai, 1992; Iai et al., 
2011), and a one-dimensional code, PSNL, developed by the first author. 80 ground motions spread over four magnitude bins and four source-to-site distance bins were propagated through each of the profiles using all three programs for both total and effective stress analyses. The ratios of peak ground surface acceleration from the total stress analyses (no generated pore pressure) to that obtained from the effective stress analyses (with pore pressure generation) for each motion that resulted in factors of safety against liquefaction ranging between 0.9 and 1.1 (to bracket the conditions at initiation of liquefaction) were found to be insensitive to the factor of safety over that narrow range of values. Figure 6 shows a histogram of $P G A$ values that indicates that the median ratio is approximately 1.08. Therefore, the $P G A$ under conditions of no pore pressure generation would, on average, be expected to be about $8 \%$ greater than the $P G A$ from the recorded motion.

\subsubsection{Penetration Resistance Associated with Softening}

In a spatially variable soil profile, pore pressures would be expected to increase more quickly in the looser portions of a liquefiable layer than in the denser portions. The onset of softening of the profile, then, would be more strongly influenced by the looser zones than the denser zones.

In order to better characterize the penetration resistance of the critical layer from the standpoint of a softening criterion for triggering of liquefaction, nonlinear effective stress analyses were performed on a series of randomized liquefiable soil profiles (Figure 7) with $\sigma_{\ln \left(N_{1}\right)_{60, c s}}=0.3$. For each randomized profile, a procedure similar to that employed by Popescu et al. (1997) was employed. The profile was analyzed and the time of liquefaction, $t_{\mathrm{L}}$, computed. Profiles with constant SPT resistance in the liquefiable layer were then analyzed to identify the uniform SPT resistances that produced the same $t_{\mathrm{L}}$ values. The percentile values of those SPT resistances were then computed. This process was repeated for 30 random realizations of four different soil profiles each subjected to 80 input motions. These analyses showed that the mean SPT percentile value was 17 , a value slightly lower than the $20^{\text {th }}$ percentile value obtained in a more extensive, two-dimensional study by Popescu et al. (1997). Given the similarity of these results (and the negligible difference s between $17^{\text {th }}$ and $20^{\text {th }}$ percentile values), critical layers with multiple SPT measurements were assigned the $20^{\text {th }}$ percentile SPT values. Standard deviations of critical layers with small numbers of SPT measurements were estimated using the procedure of Burlington and May (1970).

\subsubsection{Softening vs. Surficial Evidence}

The motion-based procedure identifies the triggering of liquefaction using changes in the frequency content of a recorded ground motion. Conventional empirical procedures for evaluation of liquefaction potential, however, are based on case histories tied to the presence or absence of surficial evidence of liquefaction. Consequently, the conventional and timingbased approaches use two different consequences of high pore pressure generation as liquefaction criteria, and the differences between them must be recognized if their results are to be compared.

Substantial changes in the amplification behavior of a soil deposit can be influenced by liquefaction of even a thin layer of loose soil. When liquefaction occurs in a thin layer that is very loose, its stiffness may drop so much that the characteristic site period increases dramatically, resulting in reductions in the transmission of high-frequency components and 
increases in low-frequency components. As shown in Figure 2, however, the development of surficial evidence requires liquefaction of a sufficiently thick layer of soil to produce enough water to flow through an overlying non-liquefiable crust and reach the ground surface. Therefore, the softening of a soil profile can generally be expected to occur prior to the development of liquefaction in a sufficiently thick zone to produce surficial evidence. Since the time corresponding to surficial evidence will be later than that corresponding to softening, the value of an evolutionary intensity measure corresponding to surficial evidence will be greater than that corresponding to softening.

In order to estimate the difference between $I M$ values at the points of softening and surficial evidence development, a series of nonlinear, effective stress analyses were performed using the computer program, PSNL. Analyses were performed on two profiles. The profiles consisted of a liquefiable layer with a uniform corrected blow counts of $10 \mathrm{blows} / \mathrm{ft}$ located beneath crusts of $2 \mathrm{~m}$ and $5 \mathrm{~m}$ thickness. The two profiles were each subjected to 30 spectrum-compatible input motions scaled to peak accelerations of $0.2 \mathrm{~g}$ and $0.3 \mathrm{~g}$ for the profiles with crusts of $2 \mathrm{~m}$ and $5 \mathrm{~m}$ thick, respectively. Using Figure 2 and the peak acceleration values listed above, the development of surficial evidence of liquefaction would require liquefaction of approximately $2 \mathrm{~m}$ of soil for the profile with the 2-m-thick crust and liquefaction of approximately $3.5 \mathrm{~m}$ of soil for the profile with the 5-m-thick crust. For each analysis, the time at which liquefaction was initiated and the time at which the required thickness of soil had reached initial liquefaction were recorded. Those times were then used to compute the ground surface evolutionary $I M$ values corresponding to the points of softening and surficial evidence development from total stress analyses. The ratios of evolutionary $I M$ values for each of the four cases are shown in Table 2. The median values of the $I M$ ratio are relatively consistent, indicating that the ground motion intensity at the point where sufficient liquefaction to produce surficial evidence has occurred is approximately $4 \%$ greater than that at which significant softening would first be expected.

\subsection{Comparison with Empirical Triggering Models}

Because motion-based case histories are different than surficial evidence-based case histories, they can be used to investigate the accuracy of conventional empirical procedures for estimation of liquefaction resistance. Two prominent groups of researchers have developed procedures for evaluation of liquefaction potential in recent years. The procedures can produce significantly different results under certain conditions, which has led to public debate and considerable uncertainty among practitioners regarding best practices. In an effort to shed light on which empirical procedure, if either, was more consistent with the motion-based case histories, the motion-based data were compared with both empirical procedures.

Interpretation of motion-based case histories requires adjustments prior to comparison with the prediction of conventional empirical procedures. A given case history may require up to three of the adjustments described in the preceding sections. The $P G A$ and response measure (softening vs. surficial evidence) adjustments move the original data point upward, and the SPT adjustment moves it to the left. All three adjustments, both individually and collectively, tend to increase the apparent liquefaction resistance of the soil. The original, unadjusted data point, therefore, represents a lower bound liquefaction resistance, i.e., the data point from a surficial evidence-based case history of liquefaction should not plot below its unadjusted motion-based data point.

The motion-based case histories were corrected to standard reference conditions $\left(\sigma^{\prime}{ }_{\text {vo }}=1\right.$ 
atm, $\left.M_{\mathrm{w}}=7.5, F C=0\right)$ for $C S R$ and $\left(N_{1}\right)_{60}$ using the procedures recommended by both Idriss and Boulanger (2008) and Cetin et al. (2004). Because those correction procedures are different, the positions of the motion-based data points shift slightly between the two procedures; both are shown in Figure 8 . Figure 8 uses open circles to show the unadjusted motion-based data points along with the CRR curves of Idriss-Boulanger and Cetin-Seed. The motion-based data can be seen to plot closer to the Cetin-Seed curve than to the IdrissBoulanger curve. However, as previously indicated, the unadjusted motion-based data points represent the level of loading at the initiation of profile softening, which occurs before and at a lower level of loading, than the development of surficial evidence of liquefaction. The presence of lower-bound data points above the Cetin-Seed curve does not support the position of that curve.

Figure 8 uses solid circles to show the positions of the motion-based case history data points after making the previously described adjustments. The adjusted data can be seen to have shifted to higher $C S R$ values and somewhat lower $\left(N_{1}\right)_{60, c s}$ values. These first-order adjustments allow more consistent comparison of the motion-based and surficial evidencebased case histories. Such a comparison shows that the adjusted motion-based data are more consistent with the Idriss-Boulanger curve than the Cetin-Seed curve. Also shown in Figure 8 is a simple exponential function fitted to only the motion-based data points - that function is not intended to be used for evaluation of cyclic resistance ratio, but rather to illustrate the trend of the motion-based case history data. The fitted curves are close to the IdrissBoulanger curve.

\subsection{Anomalous Cases}

Detailed time-frequency analyses, such as those made possible by the Stockwell transform, can allow more detailed examination of case histories where ground motions have been recorded at sites that liquefied. Observations of the presence or absence of surficial evidence of liquefaction can be supplemented by observations of the manner in which the stiffness of the profile appeared to have changed during and after earthquake shaking. These supplementary observations can confirm the occurrence of liquefaction, or even call into question whether liquefaction truly did or did not occur, when surficial evidence is not conclusive. They can also aid in the interpretation of anomalous cases.

Any purely numerical procedure for identifying the triggering of a phenomenon as complex as liquefaction runs the risk of being confounded by behavior and/or observations that are not consistent with the phenomenon of interest. Such cases can lead to the occurrence of false positives, i.e., observations of surficial evidence of liquefaction where liquefaction did not actually occur, and false negatives, i.e., the occurrence of liquefaction at sites where no surficial evidence was observed. False positives can also result from changes in frequency content caused by phenomena other than liquefaction, such as the arrival of surface waves.

\subsubsection{IBRH2O}

Kik-Net Station IBRH20, located in Kamisu in Ibaraki prefecture, was listed by Cox et al. (2013) as a recording station with evidence of liquefaction following the 2011 Tohoku earthquake, although sand boils were noted as being observed "in the vicinity on three sides but not directly around station." Kik-Net characterizes the instrument site as being mantled 
with about $4 \mathrm{~m}$ of fill placed on quaternary sand and gravel, which extends to depths exceeding $30 \mathrm{~m}$ below the ground surface. KiK-Net indicates that the upper $8 \mathrm{~m}$ of the soil has a shear wave velocity of about $180 \mathrm{~m} / \mathrm{s}$, which increases to about $280 \mathrm{~m} / \mathrm{s}$ throughout the majority of quaternary sand and gravel. A nearby excavation showed a groundwater table depth of 4-6 m. A normalized Stockwell spectrogram for the IBRH20 motion is shown in Figure 9. The spectrogram does not show visual evidence of a sharp reduction in high frequency motion or a sharp increase in low frequency motion, let alone the coincidence of those observations in time that is frequently associated with triggering of liquefaction. The shift to lower frequencies that is observed at about $180 \mathrm{sec}$ occurs when the motion has decreased to very weak levels and is likely due to surface waves. It therefore appears that the ground motion at the location of the IBRH20 instrument was strong enough to produce significant pore pressure in a thick layer of potentially liquefiable soil, but not strong enough to actually trigger liquefaction.

\subsubsection{CHBOO8}

K-Net Station CHB008 is located just north of the old coastline in Urayasu City along Tokyo Bay. Cox et al. (2013) list the site as a site underlain by recent sediments but without evidence of ground failure in the 2011 Tohoku earthquake. Tokimatsu et al. (2012) reported that no evidence of liquefaction was observed in the neighborhood of the instrument, and presented a "normalized running spectrum" (Figure 10) that showed only gradual lengthening of the period of the motion. The running spectrum is based on the STFT and is normalized "at the spectral peak of each 10-second interval." Subsurface conditions tabulated by KikNet at CHB008 consist of approximately $1 \mathrm{~m}$ of fill underlain by $1.2 \mathrm{~m}$ of "sandy soil" (interpreted here as silty sand), underlain by about $2.5 \mathrm{~m}$ of "sand" (interpreted as clean sand) over $3.4 \mathrm{~m}$ of sandy soil. The lower layer of sandy soil is underlain by "silt" to the base of the 20-m-deep exploration. The groundwater table was characterized by Tokimatsu et al. (2012) as being $2.4 \mathrm{~m}$ below the ground surface, which would be close to the top of the sand layer. The Kik-Net profile shows uncorrected SPT resistances less than $10 \mathrm{blows} / \mathrm{ft}$ in the sandy soil layers, less than 5 blows/ft in the deep silt layer, and ranging from about 10-20 in the sand layer blows/ft. Available SPT (Tokimatsu et al., 2012) data from the area around CHB008 shows somewhat higher penetration resistances in the 2-6 $\mathrm{m}$ depth range than observed in areas of Urayasu south of the old coastline, but the average SPT resistance is still less than 10 blows/ft down to about $4 \mathrm{~m}$ depth. It is likely that some component of the higher penetration resistance, and the apparently increased liquefaction resistance, of these soils is due to aging effects. Nevertheless, factor of safety calculations showed factors of safety against liquefaction being slightly below 1.0 over significant depth ranges for the CHB008 vicinity in relatively clean $(\mathrm{FC}<15 \%)$ sands, and over much shorter depth ranges for siltier sands. Examination of time-frequency behavior using the Stockwell spectrum (Figure 11), which provides much greater resolution than the techniques used by Tokimatsu et al. (2012), does reveal a relatively sudden reduction in the amplitude of higher frequency motion at a time of between 116 and $118 \mathrm{sec}$. Examination of the azimuthal variation of modal frequency shows the presence of polarized low frequency waves prior to the estimated time of liquefaction, which may be the result of surface waves in the basin. Figure 12 shows the azimuthal modal frequency starting from the time of strong shaking around $80 \mathrm{sec}$. Normalizing the horizontal frequency spectrum by the vertical frequency spectrum provides an estimate of the fundamental frequency of the site, and not the frequency content shift due to surface waves. The azimuthal plot of the model $\mathrm{H} / \mathrm{V}$ spectrum shows a relatively uniform frequency content decrease from around 2 to $6 \mathrm{~Hz}$ before $116 \mathrm{sec}$ to about $1 \mathrm{~Hz}$ after $118 \mathrm{sec}$. Whether the pore pressures were high enough to produce liquefaction that did not express 
itself in the form of surficial evidence cannot be determined, but the changes in frequency suggests that the amplification behavior of the profile changed quickly in all directions, a behavior typically associated with the generation of high pore pressures.

\subsubsection{Onahama Port}

Onahama Port is located near Iwaki City in Fukushima Prefecture. During the 2011 Tohoku earthquake, Onahama Port suffered damage in the form of settlement that displaced crane rails and other port facilities. While the port was affected by a tsunami, sand boils were observed from aftershocks. The Port and Airport Research Institute (PARI) operated a vertical array at Onahama Port. An instrument at a depth of $11 \mathrm{~m}$ recorded peak accelerations of $0.173 \mathrm{~g}$ in the EW and $0.204 \mathrm{~g}$ in the NS directions with corresponding ground surface accelerations of $1.560 \mathrm{~g}$ and $1.162 \mathrm{~g}$. The PARI instrument was located in an area underlain by saturated sand, but that sand was quite dense (Figure 13) at depths below about $2.8 \mathrm{~m}$. With the groundwater level at $1.2 \mathrm{~m}$, the loose, saturated portion of the profile was only about $1.6 \mathrm{~m}$ thick, and was both underlain and overlain by permeable soils. Figure 14 shows a Stockwell spectrogram of the Onahama Port ground surface motions. The fundamental frequency of the ground surface motion appears to be approximately $5 \mathrm{~Hz}$ at the beginning of the record. It then drops relatively slowly as the shaking progresses, reaching a minimum of about $1 \mathrm{~Hz}$ at about $105 \mathrm{sec}$. The fundamental frequency can then be seen to recover, increasing during the latter portion of the recorded motion to regain its original value at about $200 \mathrm{sec}$. The increase in modal frequency results from increased soil stiffness, which results from increased effective stress. Thus, the Onahama record appears to show evidence of pore pressure dissipation due to drainage while shaking was taking place. While the Onahama profile softened and produced numerous strong dilation pulses (Roten et al., 2013), it never appears to have become extremely soft at any point during the record.

\subsection{Discussion}

In summary, the motion-based case history data appears to be more consistent with the empirical prediction of Idriss-Boulanger than with Cetin-Seed. The motion-based curve is somewhat steeper than either the Idriss-Boulanger or Cetin-Seed curves, and a number of the data points at low penetration resistance lie close to the Cetin-Seed curve. It should be noted, however, that the adjustment procedures were developed on an aggregate, rather than case history-specific, basis, that additional case histories for which only CPT data is available have not been used, and that the motion-based case histories do not include cases of deep liquefaction or the effects of initial shear stresses that can lead to large differences in the predictions of the two procedures. Nevertheless, they represent an independent source of case history data that sheds light on the relative accuracy of the two procedures.

\subsection{Effects of Liquefaction}

Knowledge of the timing of liquefaction can also aid in the estimation of its effects. The development of permanent deformations, whether primarily horizontal in the case of lateral spreading or vertical in the case of post-liquefaction settlement, occurs predominantly after liquefaction has been triggered. As a result, the portion of the loading that drives permanent deformations is the portion that occurs after triggering, and it is reasonable to expect that the level of permanent deformation at a particular site should be most closely related to the level 
of shaking that occurs after the time of triggering. Knowing the time of liquefaction allows separation of the total loading, expressed in terms of an evolutionary $I M$, into pre-triggering and post-triggering portions.

\subsection{A Timing-Based Framework for Prediction of Liquefaction-Induced Deformations}

Estimation of the effects of liquefaction can be accomplished within a timing-based framework that lends itself to a convenient graphical representation. The framework allows different evolutionary $I M$ s to be used for the triggering and effects of liquefaction. Because the characteristics of a soil profile usually change significantly after the triggering of liquefaction, there is no reason to assume that an intensity measure that efficiently predicts triggering should also efficiently predict the effects of liquefaction. By identifying and using optimal IMs for both cases, uncertainty in the predicted effects can be reduced. The effects prediction framework is shown schematically for a single ground motion in Figure 15. The value of an evolutionary $I M$ for the prediction of triggering, here denoted as $I M_{\text {trig }}$, can be obtained from an empirical triggering model for an element of soil with some penetration resistance, as shown in Figure 15(a). Knowing the value at triggering, $I M_{\text {trig }}^{L}$, a plot of the time history of $I M_{\text {trig }}$ (Figure 15(b)) can be used to determine the time of triggering, $t_{L}$. The time of triggering can then be used to determine the value of an evolutionary $I M$ for the effects of liquefaction, denoted $I M_{\text {eff }}$. The post-triggering value of the effects intensity measure, i.e., the value that remains after triggering, is defined as

$$
I M_{\text {eff }}^{\text {post }}(t)=I M_{\text {eff }}^{\text {tot }}-I M_{\text {eff }}(t)
$$

where $I M_{e f f}^{t o t}$ is the total value of $I M_{e f f}$ at the end of the ground motion. The time history of $I M_{e f f}^{\text {post }}$, plotted in Figure 15(c), is graphically equivalent to the time history of $I M_{\text {eff }}$ flipped vertically; its value at $t=t_{L}$ represents the level of loading that remains after the triggering of liquefaction. The timing-based framework requires an effects prediction model for permanent deformation as a function of penetration resistance and $I M_{\text {eff }}^{\text {post }}\left(t_{L}\right)$. The results of such a model can be presented graphically in terms of deformation contours, as illustrated in Figure 15(d). Knowing the penetration resistance and the value of $I M_{\text {eff }}^{\text {post }}\left(t_{L}\right)$, the estimated permanent deformation can be determined from the deformation contours.

The dashed lines in Figure 15 illustrate the use of the timing-based framework for two elements of soil - one with a low corrected SPT resistance and the other with a higher value. Liquefaction is triggered in the looser element at a lower value of $I M_{\text {trig }}$ than in the denser element (Figure 15(a)). As a result, liquefaction of the looser element would occur at an earlier time (Figure 15(b)), which means that the remaining level of loading, characterized by $I M_{\text {eff }}^{\text {post }}\left(t_{L}\right)$, would be higher for the looser element than for the denser element (Figure 15(c)). The combination of a lower penetration resistance and a higher level of loading after triggering leads to a greater level of permanent deformation (Figure 15(d)) for the looser element $\left(\delta=\delta_{4}\right)$ than the denser element $\left(\delta=\delta_{2}\right)$.

\subsubsection{Evolutionary IMs for Effects}


Many intensity measures can be used to predict the effects of liquefaction, but some are better predictors of those effects than others. For practical utility, an $I M$ used for prediction of deformations should be predictable with a well-established ground motion prediction equation (GMPE). For accuracy, the $I M$ should also be an efficient predictor of permanent deformation. With these constraints, a limited investigation of post-triggering $I M$ efficiency was undertaken. Candidate $I M \mathrm{~s}$ were limited to those that could be expressed in evolutionary form and for which high-quality GMPEs had been developed within the past 10 years.

The relative efficiencies of three candidates $-P G A_{\mathrm{M}}, I_{\mathrm{a}}$, and $C A V-$ were investigated in a numerical study. A 2.7-m-thick layer of sand (Figure 16(a)) sloping at $2 \%$ was analyzed using the computer program FLIP (http://www.flip.or.jp/flip_english.html) with the multispring constitutive model (Iai et al., 1992; Iai et al., 2011). The sand was assumed to have corrected SPT resistances of $4,8,12,16$, and $20 \mathrm{blows} / \mathrm{ft}$, and was subjected to 80 input motions (Figure 16(b)) evenly distributed across four magnitude bins and four source-to-site distance bins, all scaled by factors of 1.0 and 2.0. These combinations resulted in 800 computed permanent displacements that varied with the SPT resistance of the sand and the intensity of the ground motion. These displacements are representative of those that can be expected to be caused by lateral spreading, but they are used here for illustrative purposes. Empirical procedures are more commonly used to estimate lateral spreading displacements for design.

To characterize the relationship between profile density and ground motion intensity, simple multi-variate power law relationships of the form

$\ln \delta=a+b\left(N_{1}\right)_{60}^{c}+d I M^{e}$

were fitted to the computed permanent displacements for six intensity measures - the total and post-triggering values of $P G A_{\mathrm{M}}, I_{\mathrm{a}}$, and $C A V$. The maximum values of the $I M \mathrm{~s}$ are the evolutionary values reached at the end of each time history, and therefore include contributions from both the pre-triggering and post-triggering portions of each motion. The post-triggering $I M \mathrm{~s}$ are based on only the motion after triggering of liquefaction. Table 3 shows the standard deviations of the logarithmic displacement residuals for each of the six $I M \mathrm{~s}$. The values based on the entire motion can be seen to produce significantly higher uncertainty in predicted displacements than the values based on only the post-triggering portions of the motions. Among the post-triggering $I M \mathrm{~s}$, Arias intensity displayed lower uncertainty than $C A V$ and considerably lower uncertainty than $P G A_{\mathrm{M}}$ in predicted displacements.

\subsubsection{Application to Lateral Spreading}

The potential benefits of the timing-based framework for prediction of the effects of liquefaction can be illustrated by means of a numerical study of lateral spreading. The site shown in Figure 16(a) was subjected to 30 ground motions made compatible with the target spectrum shown in Figure 17(a). $P G A_{\mathrm{M}}$ was used as an evolutionary triggering $I M$ and $I_{a}^{\text {post }}$ as an evolutionary effects $I M$. Those $I M$ s reflect different characteristics of each ground motion, but they are correlated to each other in the sense that when $P G A_{\mathrm{M}}$ has a low value, such as early in a time history, $I_{a}^{\text {post }}$ will have a high value. Figure 17(b) shows the values of 
$P G A_{\mathrm{M}}$ and $I_{a}^{\text {post }}$ plotted against each other for all 30 ground motions. If either of these parameters was plotted against the post-triggering version of itself (i.e., if the same $I M$ was used for both triggering and effects), the result would be a series of straight lines sloping downward at 45 degrees. Deviations from linearity in Figure 17(b) serve to illustrate differences in the manners in which the two selected $I M$ s characterize ground motions.

Assuming the saturated sand had a constant corrected penetration resistance, $\left(N_{1}\right)_{60, \mathrm{cs}}=10$ blows/ft, a value of $P G A_{\mathrm{M}}$ based on the Idriss and Boulanger triggering curve (Figure 18(a)) indicates that $I M_{\text {trig }}^{L}=P G A_{\mathrm{M}}$ would be $0.15 \mathrm{~g}$ at the center of the saturated layer. Using $P G A_{\mathrm{M}}$ as a triggering $I M$, its evolution for the 30 motions is shown in Figure 18(b) - even though the motions have very similar response spectra, the phasing of the time histories is different so $P G A_{\mathrm{M}}$ increases at different rates for the different motions. The black dots in Figure 18(b) indicate the times of liquefaction of each of the 30 motions. Figure 18(c) shows the corresponding curves of $I M_{\text {eff }}^{\text {post }}$ for each of the 30 motions. Again, differences in the phasing lead to differences in the curves. The closed circles in Figure 18(c) show the values of $I M_{\text {eff }}^{\text {post }}\left(t_{L}\right)$ that, combined with the SPT resistance, indicate the permanent displacements in Figure 18(d). The predicted displacements range from about $0.3 \mathrm{~m}$ to $0.9 \mathrm{~m}$ with a dispersion, $\sigma_{\ln \delta}=0.23$.

The example in Figure 18 implicitly assumed that the SPT resistance and $C R R$ were both known with certainty. SPT resistance values are actually quite uncertain due to spatial variability and measurement errors, and that uncertainty will lead to additional uncertainty in lateral spreading displacements. Figure 19 shows the result of analyses in which $\left(N_{1}\right)_{60, \text { cs }}$ was randomized assuming a lognormal distribution with $\sigma_{\ln N}=0.3$ and $C R R$ was assumed to be lognormally distributed with $\sigma_{\ln C R R}=0.239$ (Boulanger and Idriss, 2012). The variability in $\left(N_{1}\right)_{60, c s}$ and $C R R$ values can be seen to increase the variability in displacements, as indicated in the increased breadth of the cluster of data points in Figure 19(d). Those compute displacements range from less than $0.2 \mathrm{~m}$ to just over $1 \mathrm{~m}$ with a dispersion, $\sigma_{\ln \delta}=0.49$, that is twice as large as that obtained with no uncertainty in SPT resistance.

Figure 20 shows histograms for lateral spreading displacement for both cases - no uncertainty in $\left(N_{1}\right)_{60, \text { cs }}$ or $C R R$ and uncertainty in both $\left(N_{1}\right)_{60, \text { cs }}$ and $C R R$. The distributions of permanent displacement can be seen to broaden as more uncertainty is introduced into the input parameters. The distributions of displacement predicted by the total value of $I M_{\text {eff }}$ are also shown in Figure 20 and the dispersion values are tabulated in the figures. The dispersion in displacements predicted using the post-triggering values of $I M_{\text {eff }}$ is much lower than those predicted using the total $I M_{\text {eff }}$ values.

\subsection{Discussion}

The simple numerical study described in the preceding section showed that uncertainty in an important effect of liquefaction could be significantly reduced by correlating it to the level of loading that remains after triggering of liquefaction instead of the total level of loading. It also showed that a timing-based framework can allow the consistent use of different intensity measures for triggering and effects of liquefaction. Such analyses can be performed with 
selected suites of ground motion time histories as illustrated here. The framework can also be used with more empirical procedures for estimation of liquefaction effects; that process, however, will require the development of ground motion prediction equations for the conditional quantity, $I M_{\text {eff }}^{\text {post }} \mid I M_{\text {trig }}$.

\subsection{Summary and Conclusions}

Timing has been a long neglected dimension of liquefaction hazard evaluation. Despite the well-recognized fact that the characteristics of liquefiable soil deposits often change dramatically after the initiation of liquefaction, hazard evaluation procedures do not distinguish between the pre-triggering and post-triggering loading. Until recently, however, data that would allow such distinctions to be made has not been available.

Time-frequency analyses offer the possibility of identifying the time at which strong changes in ground motion frequency content occur. Significant drops in mean horizontal frequency and the frequency associated with peak $\mathrm{H} / \mathrm{V}$ ratios, when confirmed as occurring in all azimuthal directions, can be taken as evidence of the triggering of liquefaction. Using evolutionary intensity measures, the value of the intensity measure at the time of initiation can be computed.

The onset of liquefaction, as evidenced by soil profile softening, however, represents a different condition than the development of surficial evidence of liquefaction. As a result, adjustment of ground motion-based triggering values is required in order to compare motionbased data with surficial evidence-based data. After making such adjustments the CRR values from 18 motion-based case histories were similar to those predicted by Idriss and Boulanger (2008).

Establishment of the time of liquefaction allows separation of evolutionary ground motion intensity measures into pre- and post-triggering portions. A framework that allows correlation of permanent deformations to the level of loading that remains after triggering of liquefaction was introduced and shown to produce less uncertain estimates of those deformations than procedures based on the entire ground motion. This framework appears to offer the potential for development of improved empirical procedures for estimation of the effects of soil liquefaction.

\subsection{Acknowledgments}

The research described in this paper was partially sponsored by the National Science Foundation under grants CMMI-0936408 and EAR-1331412, and the Pacific Earthquake Engineering Research (PEER) Center under the Next Generation Liquefaction (NGL) project. The work also benefited from studies undertaken by Pelin Tuhumcu Ozener of Yildiz Technical University and Bita Astaneh Asl of the University of Washington.

\subsection{References}

Boulanger, R. W., and Idriss, I. M. (2012). "Probabilistic SPT-based liquefaction triggering procedure." Journal of Geotechnical and Geoenvironmental Engineering, ASCE, 138(10), $1185-1195$. 
Boulanger, R. W., and Ziotopoulou, K. (2012). "PM4Sand (version 2): A sand plasticity model for earthquake engineering applications." Report No. UCD/CGM-12/01, Center for Geotechnical Modeling, Department of Civil and Environmental Engineering, University of California, Davis, CA, May, 100 pp.

Burlington, R.S. and May, D.C., JR. (1970). Handbook of Probability and Statistics, McGraw-Hill, New York, 463 pp.

Cetin, K.O., Seed, R.B., Der Kiureghian, A., Tokimatsu, K., Harder, L.F., Kayen, R.E., and Moss, R.E.S. (2004). "Standard penetration test-based probabilistic and deterministic assessment of seismic soil liquefaction potential," Journal of Geotechnical and Geoenvironmental Engineering, ASCE, 130(12), 1314-1340.

Green, R.A., Mitchell, J.K., and Polito, C.P. (2000). "Energy-based excess pore pressure generation model for cohesionless soils," Proceedings, John Booker Memorial Symposium, Sydney, NSW, Australia, 16-17.

Hancock, J. and Bommer, J. J. (2004), "The effective number of cycles of earthquake ground motion," Earthquake Engineering Structural Dynamics, 34.

Iai, S., Matsunaga, Y., and Kameoka, T. (1992). "Strain space plasticity model for cyclic mobility," Soils and Foundations, 32(2), 1-15.

Iai, S., Tobita, T., Ozutsumi, O., Ueda, K. (2011). "Dilatancy of granular materials in a strain space multiple mechanism model," International Journal for Numerical and Analytical Methods in Geomechanics, 35.

Idriss, I.M. and Boulanger, R.W. (2008). Soil liquefaction during earthquakes, Monograph MNO-12, Earthquake Engineering Research Institute, Oakland, CA, 261 pp.

Kayen, R. E. and Mitchell, J. K. (1997). "Assessment of liquefaction potential during earthquakes by Arias intensity," Journal of Geotechnical and Geoenvironmental Engineering, ASCE, 123(12), 1162-1174.

Kramer, S.L. and Mitchell, R.A. (2006). "Ground motion intensity measures for liquefaction hazard evaluation," Earthquake Spectra, 22(2), 413-438.

Liu, A. H., Stewart, J. P., Abrahamson, N. A., and Moriwaki, Y. (2001), "Equivalent Number of Uniform Stress Cycles for Soil Liquefaction Analysis," ," Journal of Geotechnical and Geoenvironmental Engineering, ASCE, 127(12).

Nakamura, Y. (1989). "A method for dynamic characteristics estimation of subsurface using microtremor on the ground surface," Quarterly Report of RTRI, 30(1), 25-33.

Ozener, P., Greenfield, M.W., Sideras, S.S., and Kramer, S.L. (2016). "Identification of time of liquefaction triggering," Soil Dynamics and Earthquake Engineering, in review.

Popescu, R., Prevost, J.H., and Deodatis, G. (1997). "Effects of spatial variability on soil liquefaction: Some design recommendations," Geotechnique, 47(5), 1019-1036.

Roten, D., Fah, D., and Bonilla, L.F. (2013). "High-frequency ground motion amplification during the 2011 Tohoku earthquake explained by soil dilatancy," Geophysical Journal International, Vol. 193, No. 2, pp. 898-904.

Stockwell, RG, L Mansinha, and RP Lowe (1996). Localization of the complex spectrum: the S transform, IEEE Transactions on Signal Processing, 44 (4), 998-1001.

Tokimatsu, K., Tamura, S., Suzuki, H., and Katsumata, K. (2012). "Building damage associated with geotechnical problems in the 2011 Tohoku Pacific Earthquake," Soils and 
Foundations, Vol. 52, No. 5, pp. 956-974.

Yamazaki, H. and Gotoh, Y. (2011) "Study on liquefaction of soil subjected to seismic motion in the 2011 off the Pacific coast of Tohoku earthquake," Technical Note No. 1242, Port and Airport Research Institute, 23 pp.

Youd, T. L., Hansen, C. M., and Bartlett S. F. (2002). Revised multilinear regression equations for prediction of lateral spread displacement." Journal of Geotechnical and Geoenvironmental Engineering. 128(12), 1007-1017. 


\section{List of Tables}

Table 1. Liquefaction-influenced ground motions and interpreted times of initiation of liquefaction.

Table 2. Ratios of $C S R$ at expected time of surficial evidence to $C S R$ at time of softening.

Table 3. Uncertainty in predicted lateral spreading displacements for different intensity measures.

\section{List of Figures}

Figure 1. Variation of (a) acceleration, (b) magnitude-corrected peak ground acceleration with time, (c) Arias intensity, and (d) cumulative absolute velocity.

Figure 2. Relationship between thickness of liquefiable layer and thickness of overlying layer at sites for which surface manifestation of level-ground liquefaction has been observed (after Ishihara, 1985).

Figure 3. Variation of ratio of characteristic site period and frequency with changes in lowstrain stiffness due to pore pressure generation.

Figure 4. Time-frequency analysis of three-part function: (a) signal, (b) STFT spectrogram, (c) wavelet scalogram, and (d) Stockwell spectrum.

Figure 5. Normalized Stockwell spectra for (a) Kawagishi-cho and (b) IBR014 records. Spectra are normalized by peak Stockwell amplitude at each time step. Red color denotes high Stockwell amplitude, blue indicates low amplitude.

Figure 6. Histogram of computed PGA (total/effective stress-based) ratios at initiation of liquefaction.

Figure 7. Typical set of randomized shear wave velocity profiles (4-m-thick liquefiable layer under 5-m-thick dry crust) with median highlighted.

Figure 8. Adjusted motion-based case history data interpreted using procedures of: (a) Idriss and Boulanger (2008) and Cetin et al. (2004).

Figure 9. Time histories and normalized Stockwell spectrogram for IBRH20 recording in 2011 Tohoku earthquake.

Figure 10. Normalized running spectrum of CHB008 motion (after Tokimatsu et al., 2012).

Figure 11. Time histories and normalized Stockwell spectrogram forCHB008 recording in 2011 Tohoku earthquake.

Figure 12. Plots of azimuthal variation of modal frequency based on horizontal and H/V Stockwell spectrograms. 
Figure 13. Subsurface profile at Onahama Port (Yamazaki and Gotoh, 2011).

Figure 14. Stockwell spectrogram for Onahama Port surface motions.

Figure 15. Timing-based framework for prediction of effects of liquefaction: (a) liquefaction triggering resistance curve, (b) evolution of triggering $I M$, (c) variation of remaining effects $I M$ with time, and (d) deformation relationship.

Figure 16. (a) Soil profile for lateral spreading analyses, and (b) input motion response spectra (scaling factor $=1.0$ only).

Figure 17. 30 spectrum-compatible motions: (a) target spectrum and statistics of individual spectra, and (b) relationship between triggering and post-triggering effects intensity measures.

Figure 18. Timing-based framework for prediction of effects of liquefaction with no uncertainty in SPT resistance or CRR: (a) liquefaction triggering resistance curve, (b) evolution of triggering IM, (c) variation of remaining effects IM with time, and (d) deformation relationship. IM values correspond to center of liquefiable layer.

Figure 19. Timing-based framework for prediction of effects of liquefaction with uncertainty in SPT resistance and CRR: (a) liquefaction triggering resistance curve, (b) evolution of triggering IM, (c) variation of remaining effects IM with time, and (d) deformation relationship. IM values correspond to center of liquefiable layer.

Figure 20. Histograms illustrating effects of uncertainties in input motions, SPT resistances, and CRR on uncertainties in predicted displacements. 

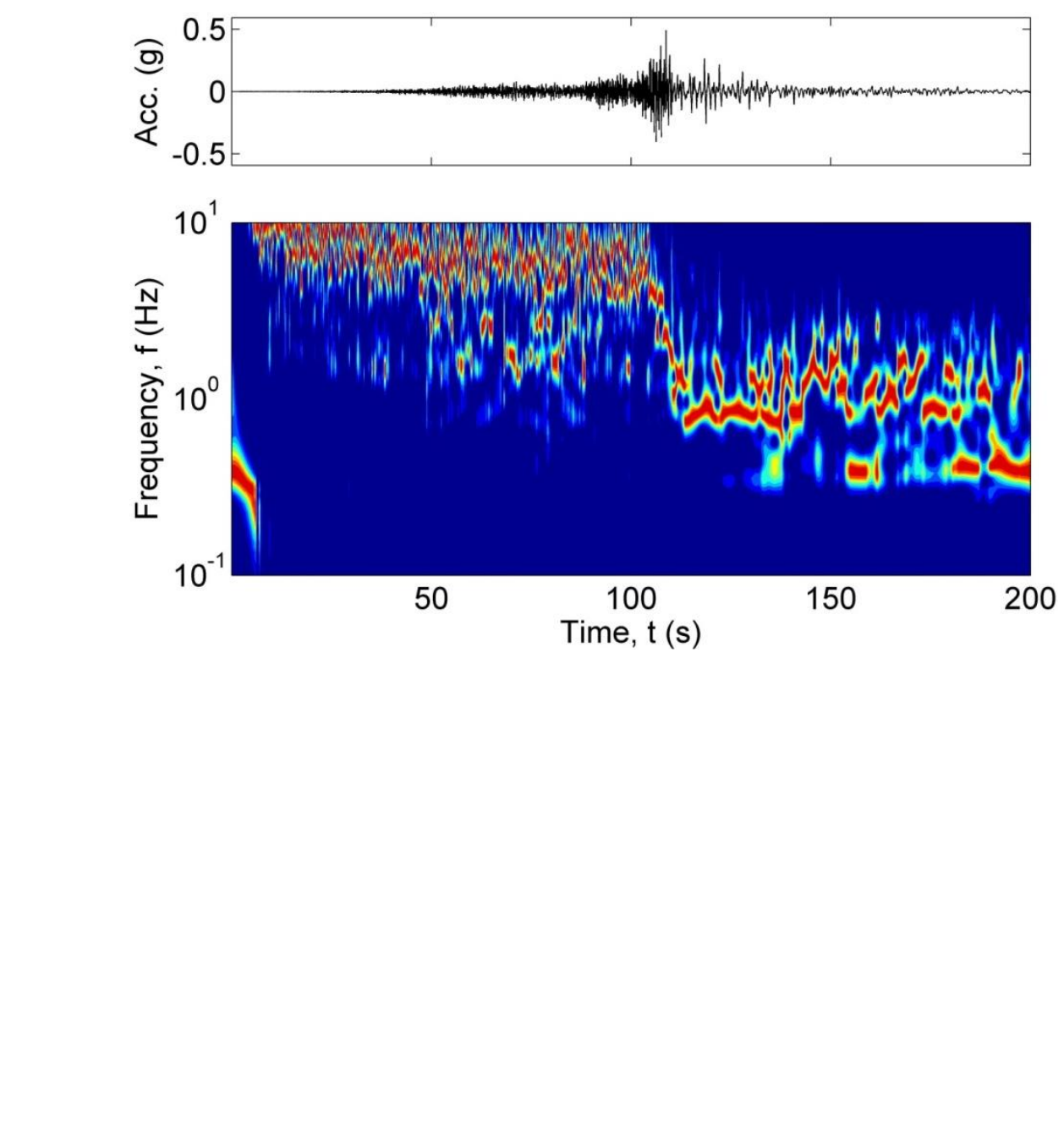

\section{Graphical Abstract}

.


Table 1. Liquefaction-influenced ground motions and interpreted times of initiation of liquefaction

\begin{tabular}{|l|c|l|c|}
\hline \multicolumn{1}{|c|}{ Earthquake } & $\boldsymbol{M}_{\mathbf{w}}$ & \multicolumn{1}{c|}{ Station } & $\boldsymbol{t}_{\mathbf{L}}(\mathbf{s})$ \\
\hline Christchurch (2011) & 6.2 & CCCC & 19.3 \\
\hline Christchurch (2011) & 6.2 & CHHC & 20.2 \\
\hline Christchurch (2011) & 6.2 & CMHS & 19.1 \\
\hline Darfield (2010) & 7 & HPSC & 30.1 \\
\hline Kobe (1995) & 6.9 & Higashi Kobe Bridge & 9.9 \\
\hline Kobe (1995) & 6.9 & Kobe JIS & 2.7 \\
\hline Kobe (1995) & 6.9 & Port Island & 14.5 \\
\hline Loma Prieta (1989) & 6.9 & ANAS & 12.4 \\
\hline Loma Prieta (1989) & 6.9 & Treasure Island & 13.5 \\
\hline Nihonkai-Chibu (1983) & 7.7 & Hachirogata & 56.9 \\
\hline Niigata (1964) & 7.7 & Kawagishi-cho & 10.4 \\
\hline Superstition Hills (1987) & 6.6 & Wildlife & 13.8 \\
\hline Tohoku (2011) & 9 & CHB024 & 120 \\
\hline Tohoku (2011) & 9 & IBR014 & 105 \\
\hline Tohoku (2011) & 9 & MYG013 & 46.9 \\
\hline Tokachi-Oki (1968) & 8.3 & Aomori Harbor & 36.5 \\
\hline Tokachi-Oki (2003) & 8.3 & HKD086 & 34.9 \\
\hline Western Tottori (2000) & 6.6 & Sakaiminato & 19.1 \\
\hline
\end{tabular}


Table 2. Ratios of $C S R$ at expected time of surficial evidence to $C S R$ at time of softening.

\begin{tabular}{|c|c|c|c|}
\hline Crust thickness & $\left(\boldsymbol{N}_{\mathbf{1}}\right)_{\mathbf{6 0}, \mathrm{cs}}$ & Median $\alpha=$ CSR $^{\text {surf }} / \mathrm{CSR}^{\text {soft }}$ & $\sigma_{\ln \alpha}$ \\
\hline $2 \mathrm{~m}$ & 7 & 1.04 & 0.046 \\
\hline $5 \mathrm{~m}$ & 7 & 1.04 & 0.17 \\
\hline
\end{tabular}


Table 3. Uncertainty in predicted lateral spreading displacements for different intensity measures.

\begin{tabular}{|c|c|c|c|c|c|c|}
\hline \multirow{2}{*}{$I M$} & \multicolumn{3}{|c|}{ Total Motion Values } & \multicolumn{3}{c|}{ Post-Triggering Values } \\
\cline { 2 - 7 } & $P G A_{M}^{\text {tot }}$ & $\boldsymbol{I}_{a}^{\text {tot }}$ & $C A V^{\text {tot }}$ & $P G A_{M}^{\text {post }}$ & $I_{a}^{\text {post }}$ & $C A V^{\text {post }}$ \\
\hline$\sigma_{\ln \delta}$ & 0.981 & 0.829 & 1.040 & 0.818 & 0.602 & 0.705 \\
\hline
\end{tabular}



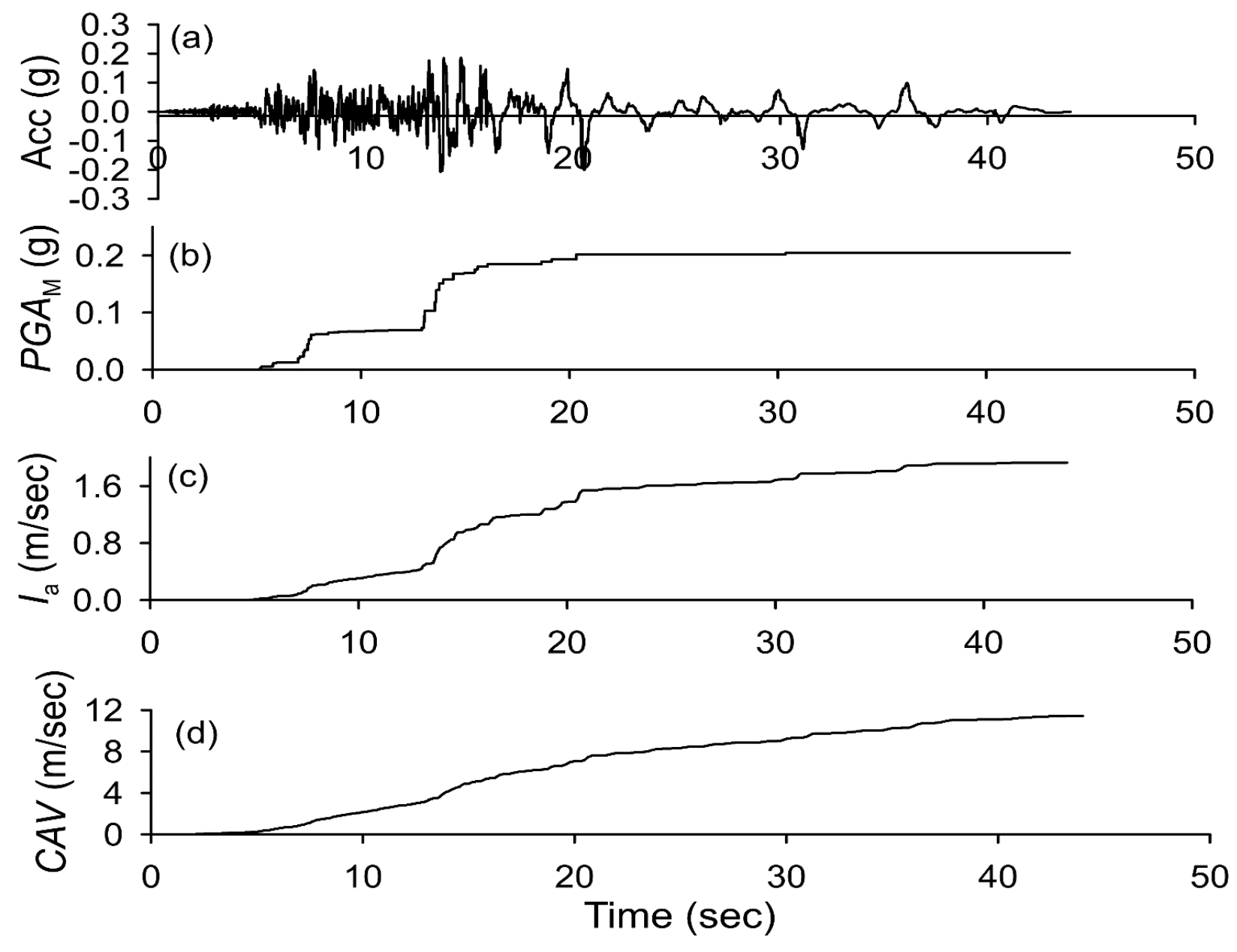


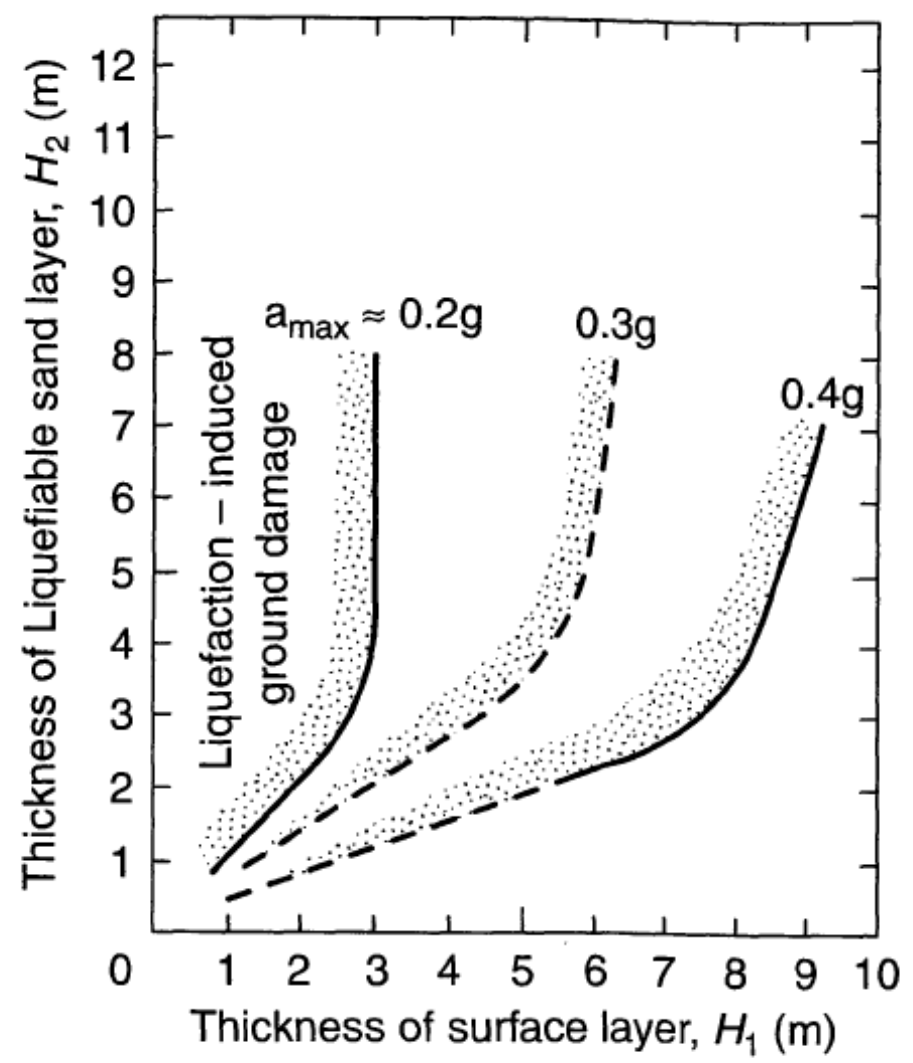

(a)
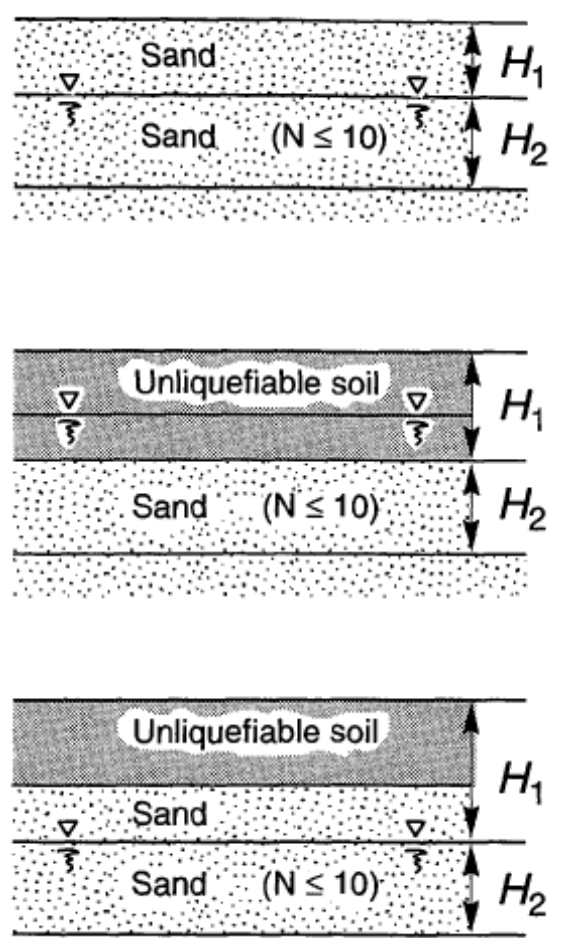

(b) 


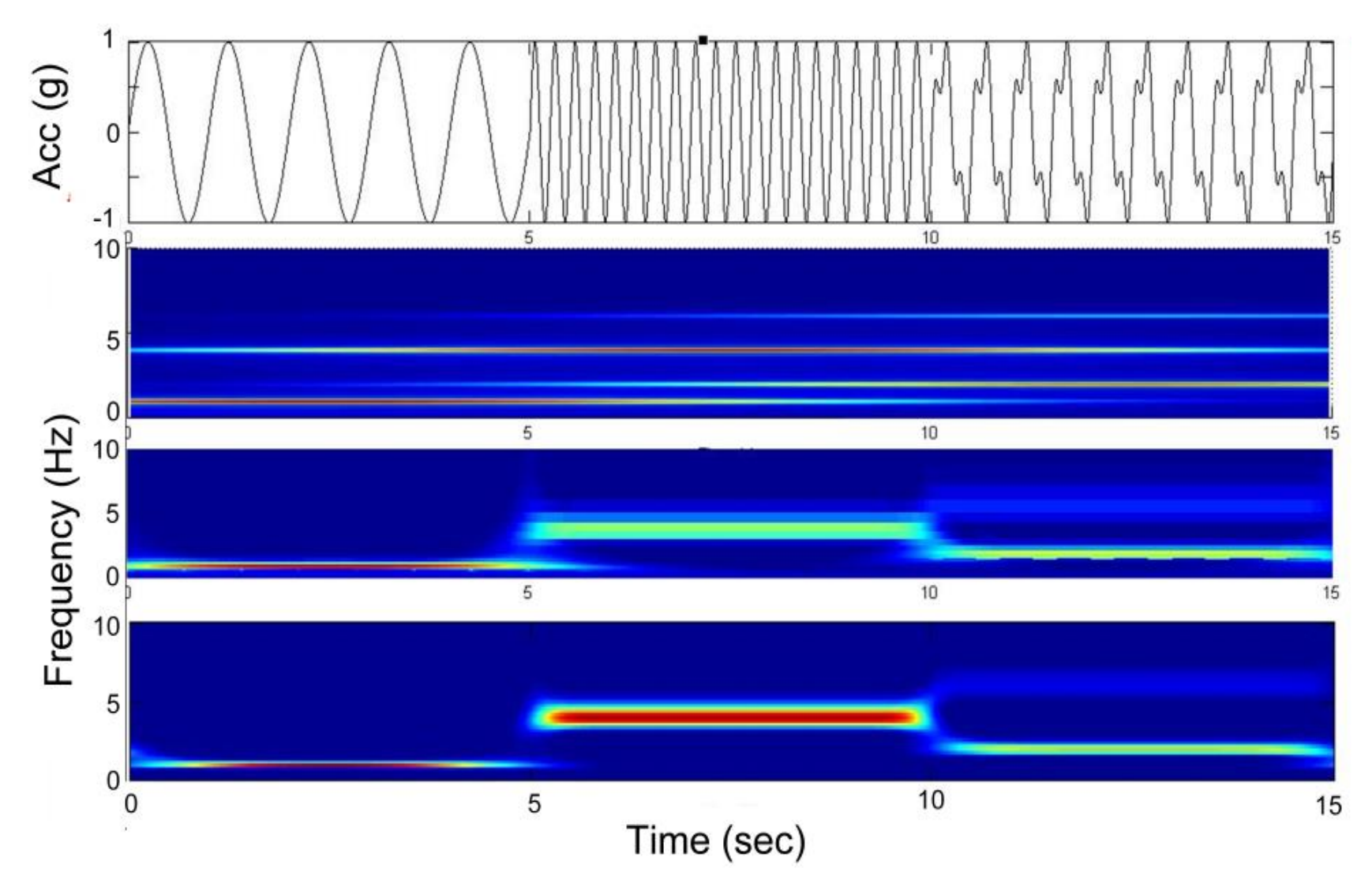

Figure

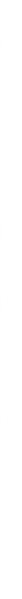

(

Time (sec)

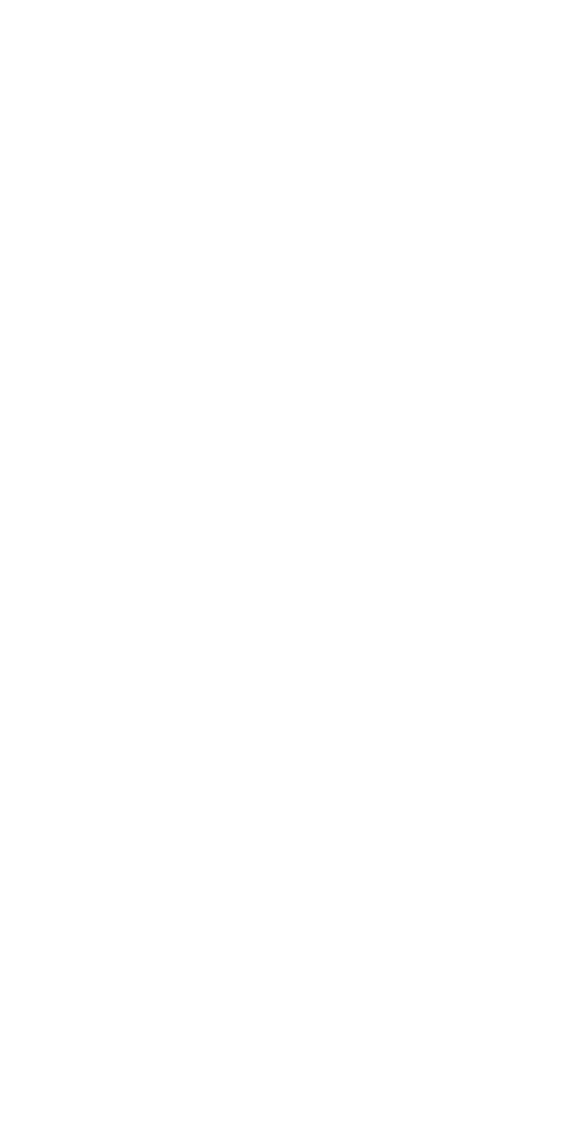



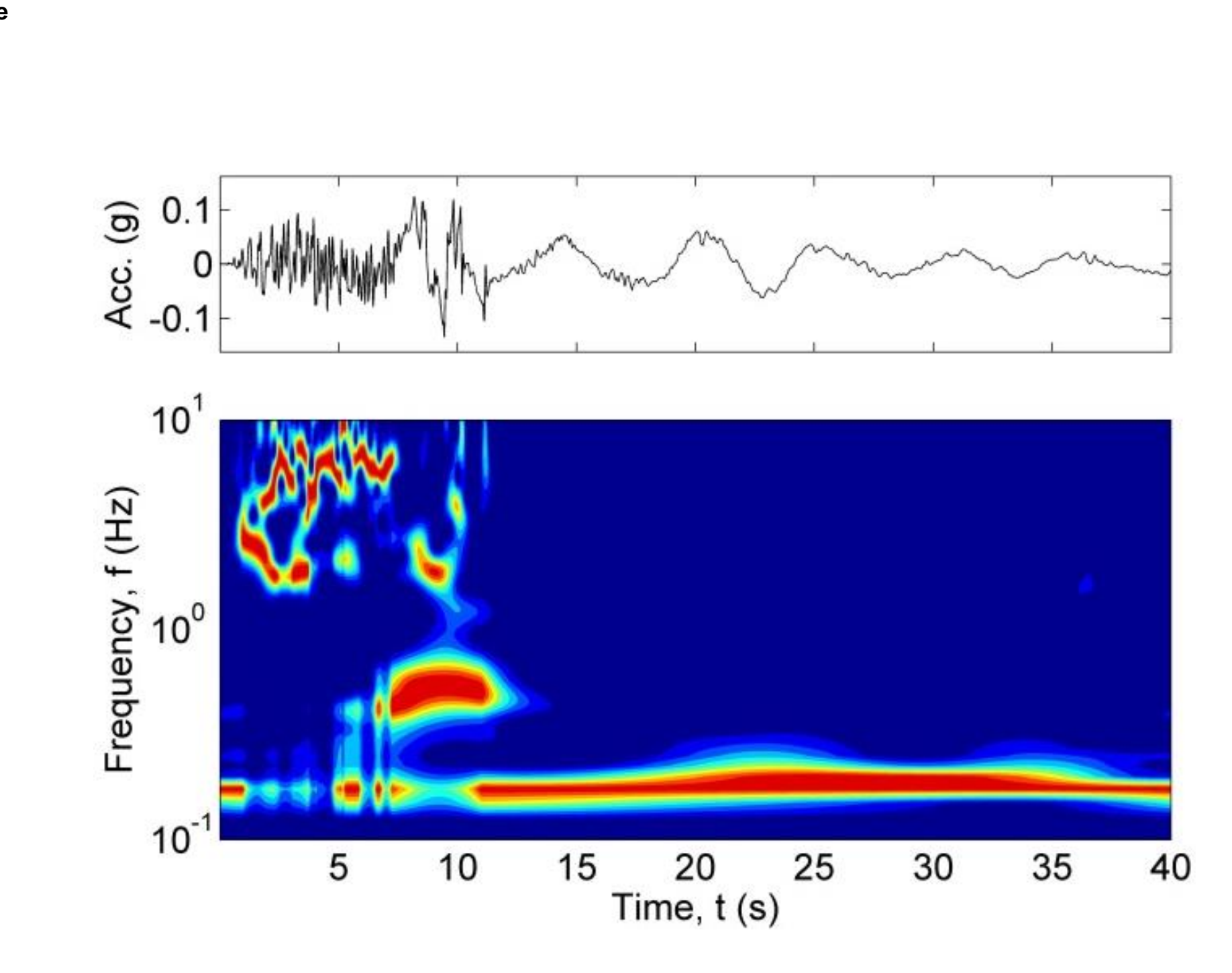

$$
\begin{array}{lllc}
5 & 10 & 15 & 20 \\
& & & \\
\text { Time, } t(\mathrm{~s})
\end{array}
$$

.

.

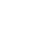
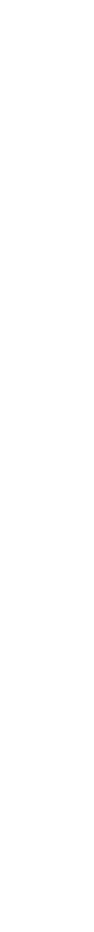

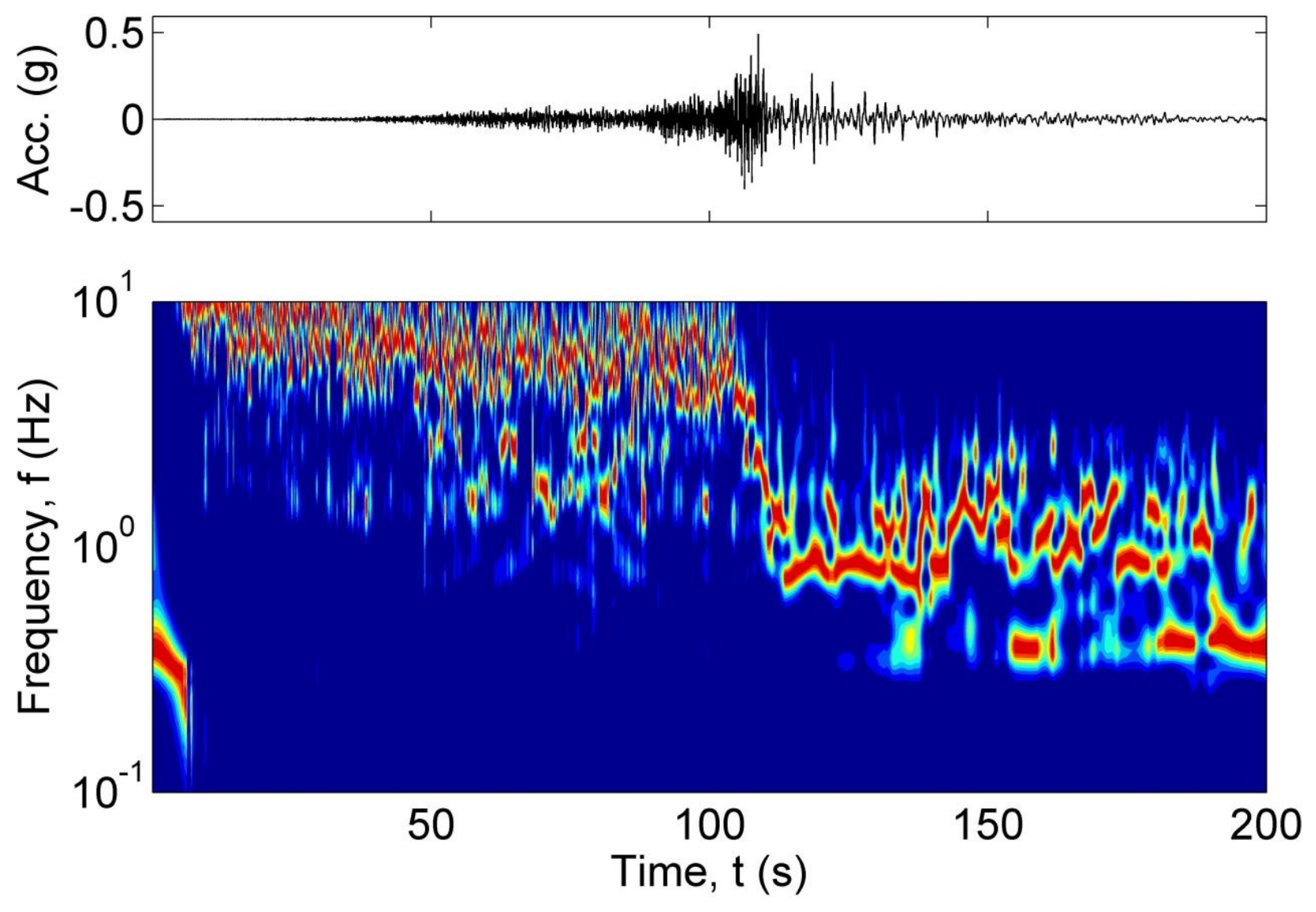
Figure

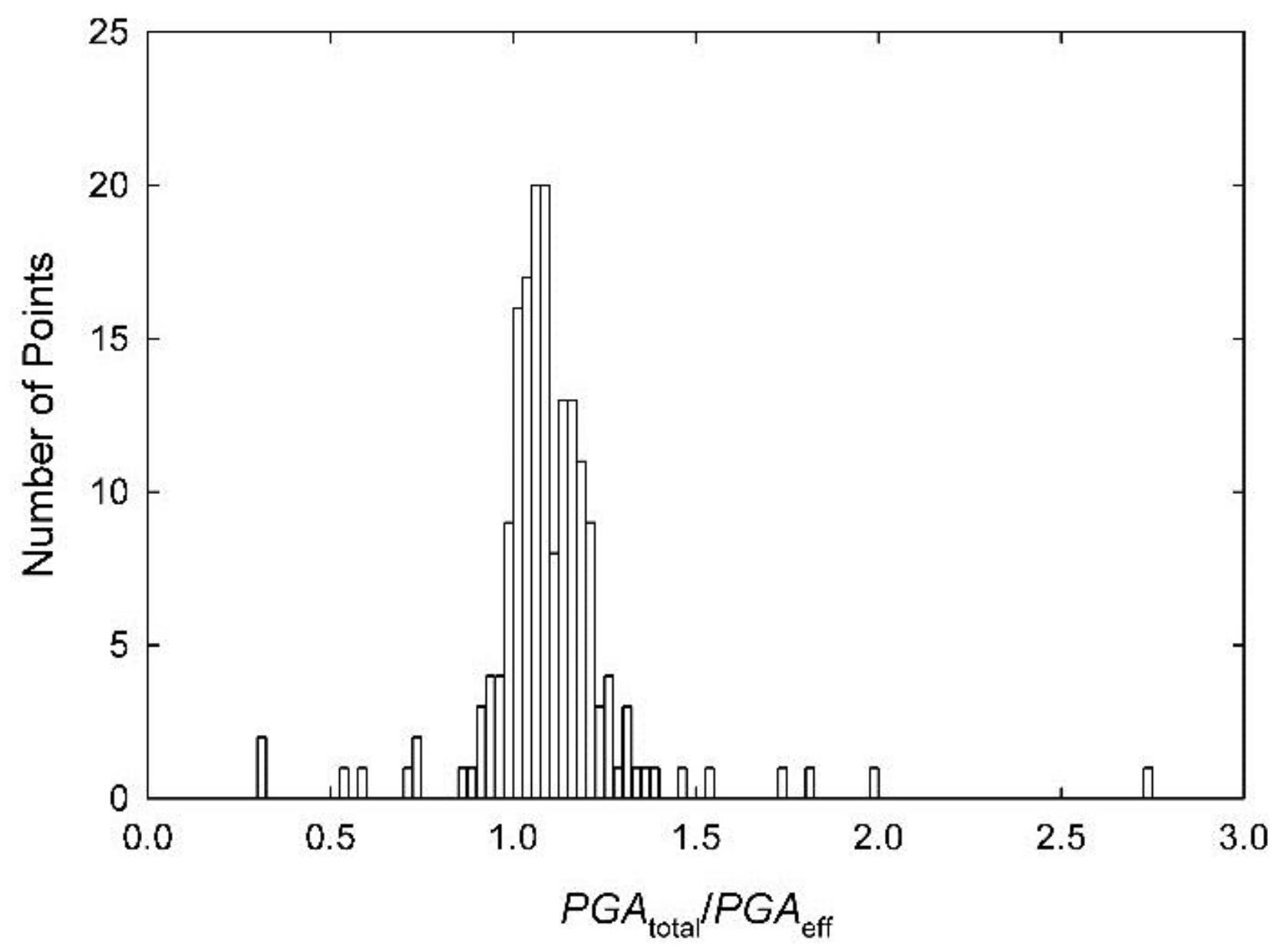




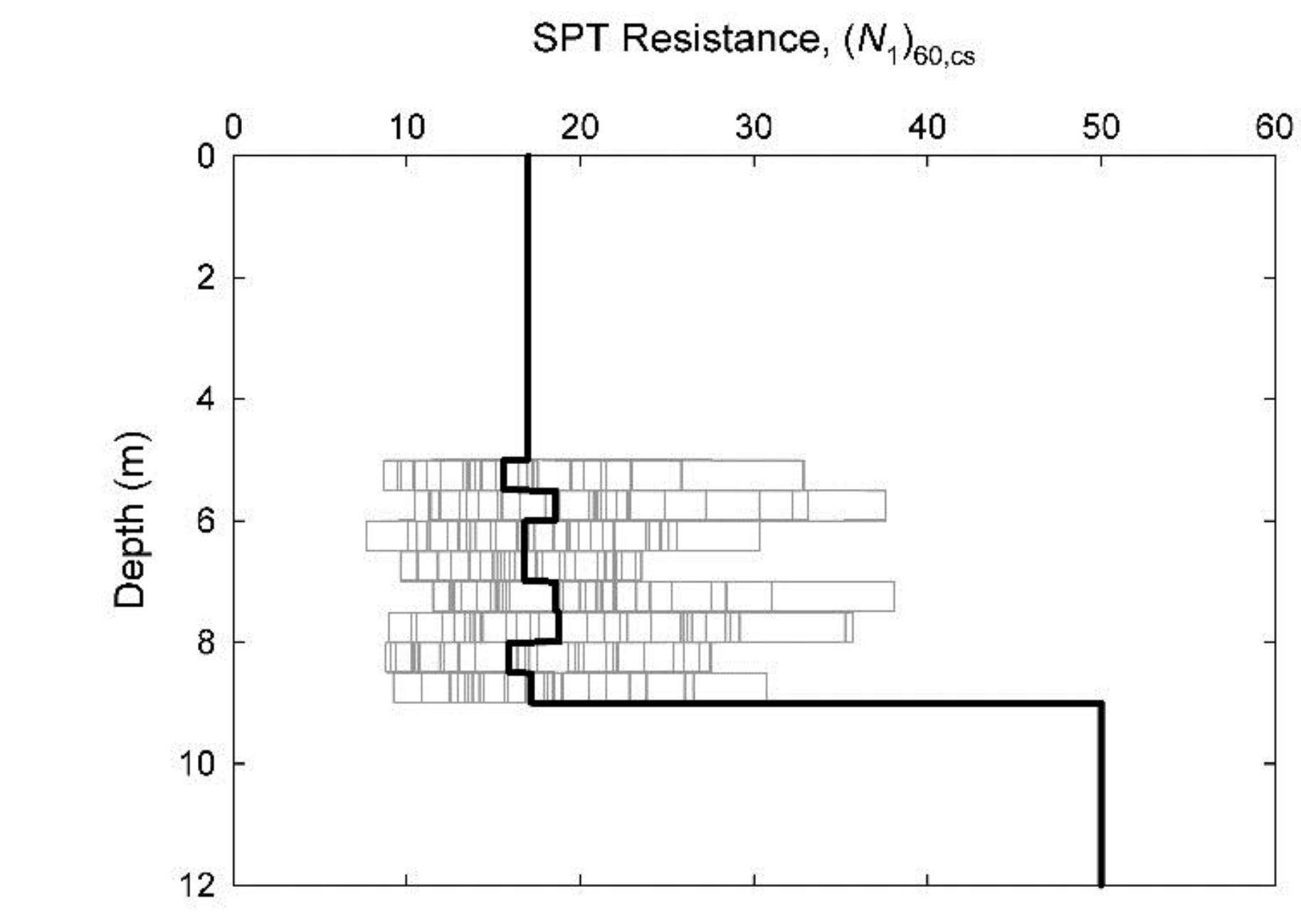

Figure
\[ \text { SPT Resistance, }\left(N_{1}\right)_{60, c s} \]

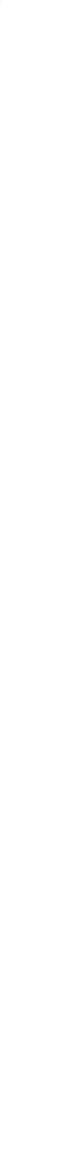

.

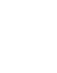




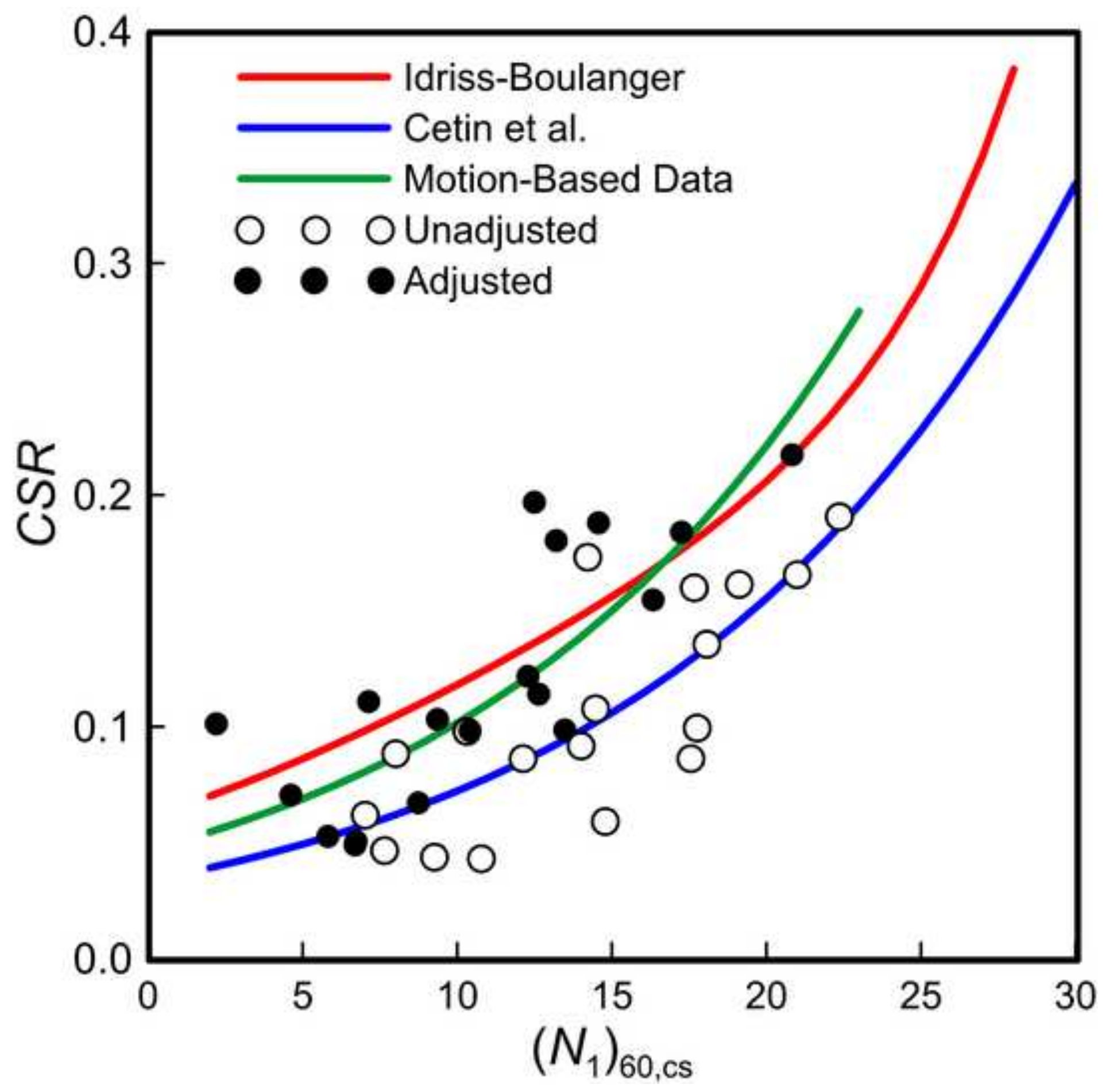




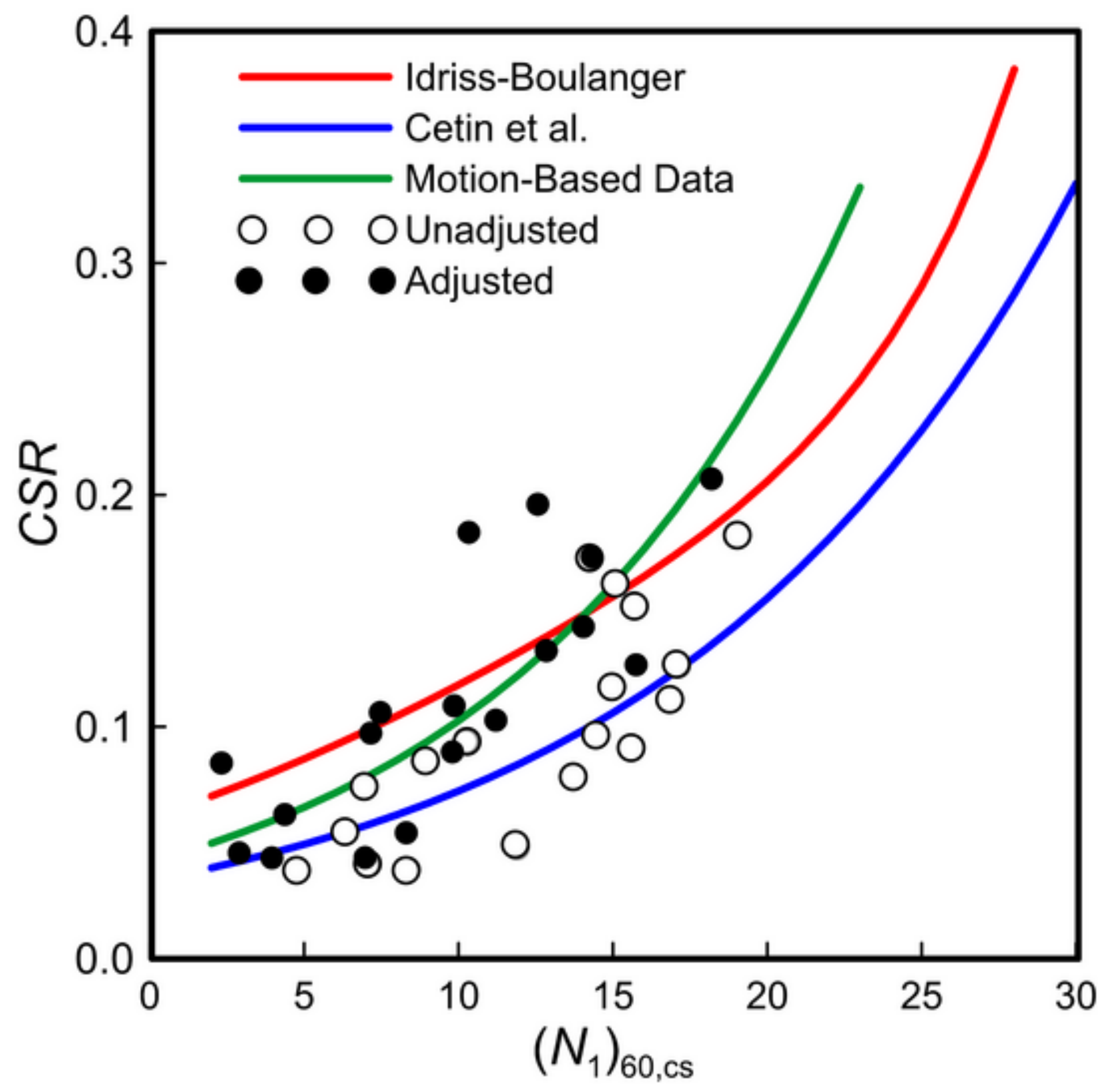



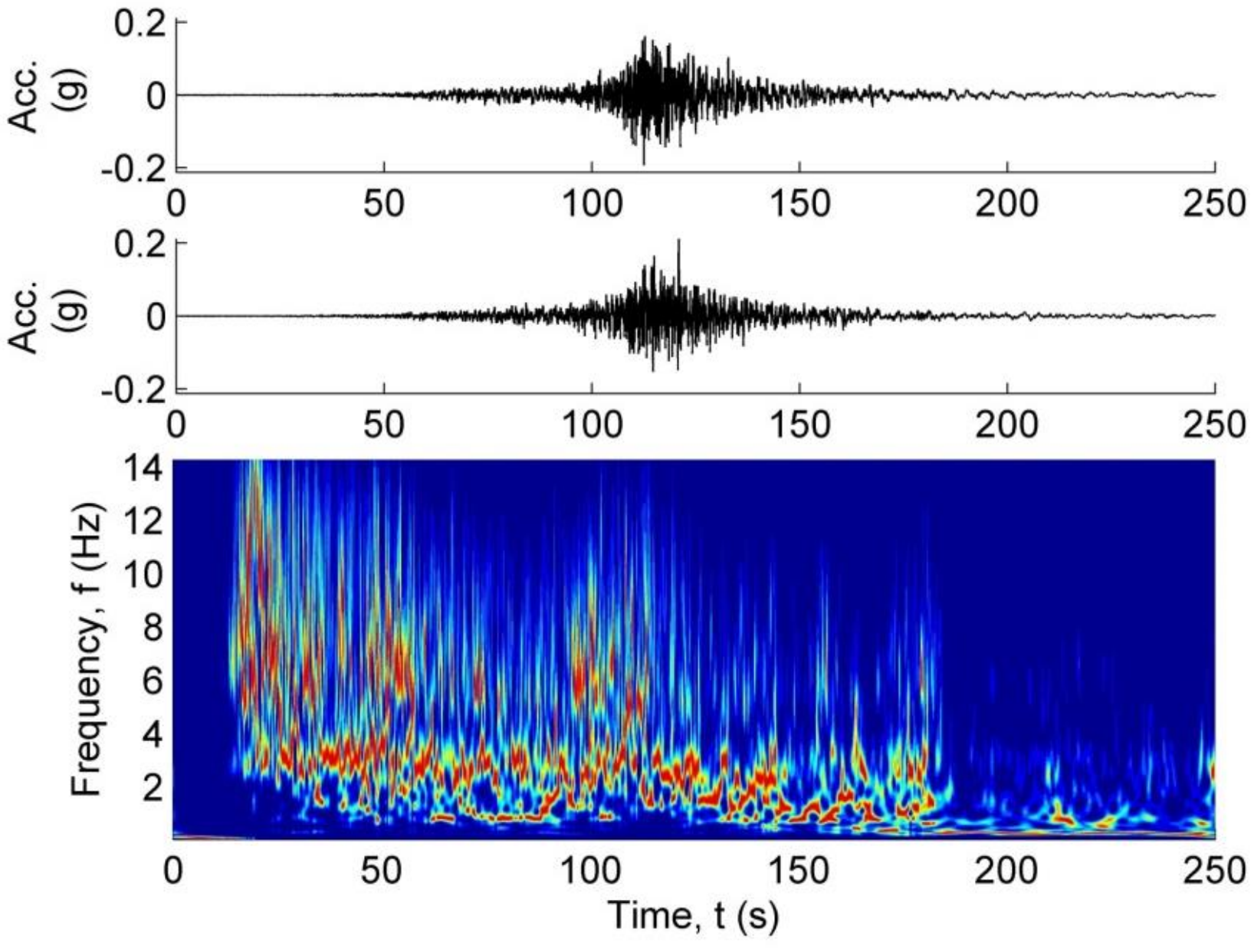


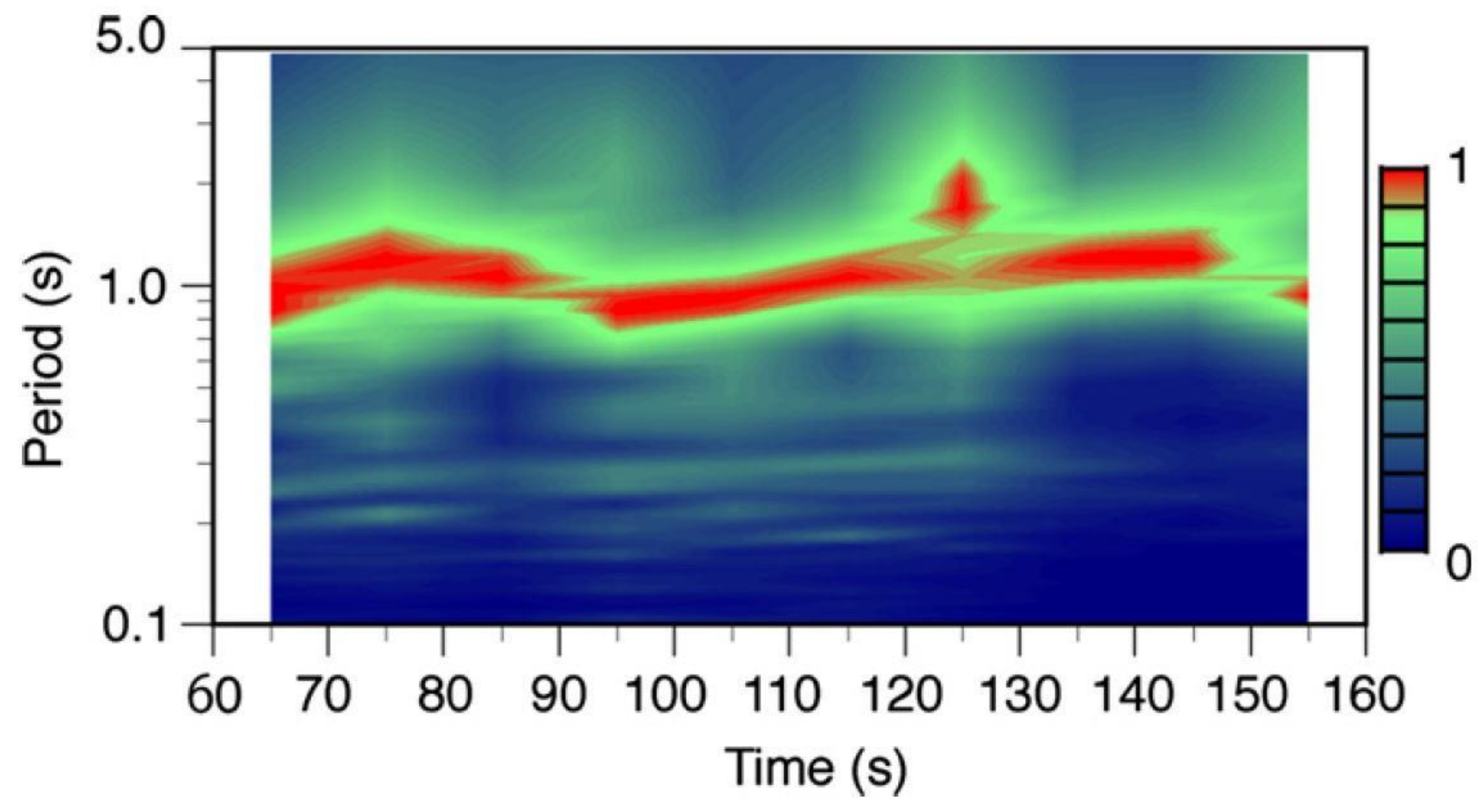



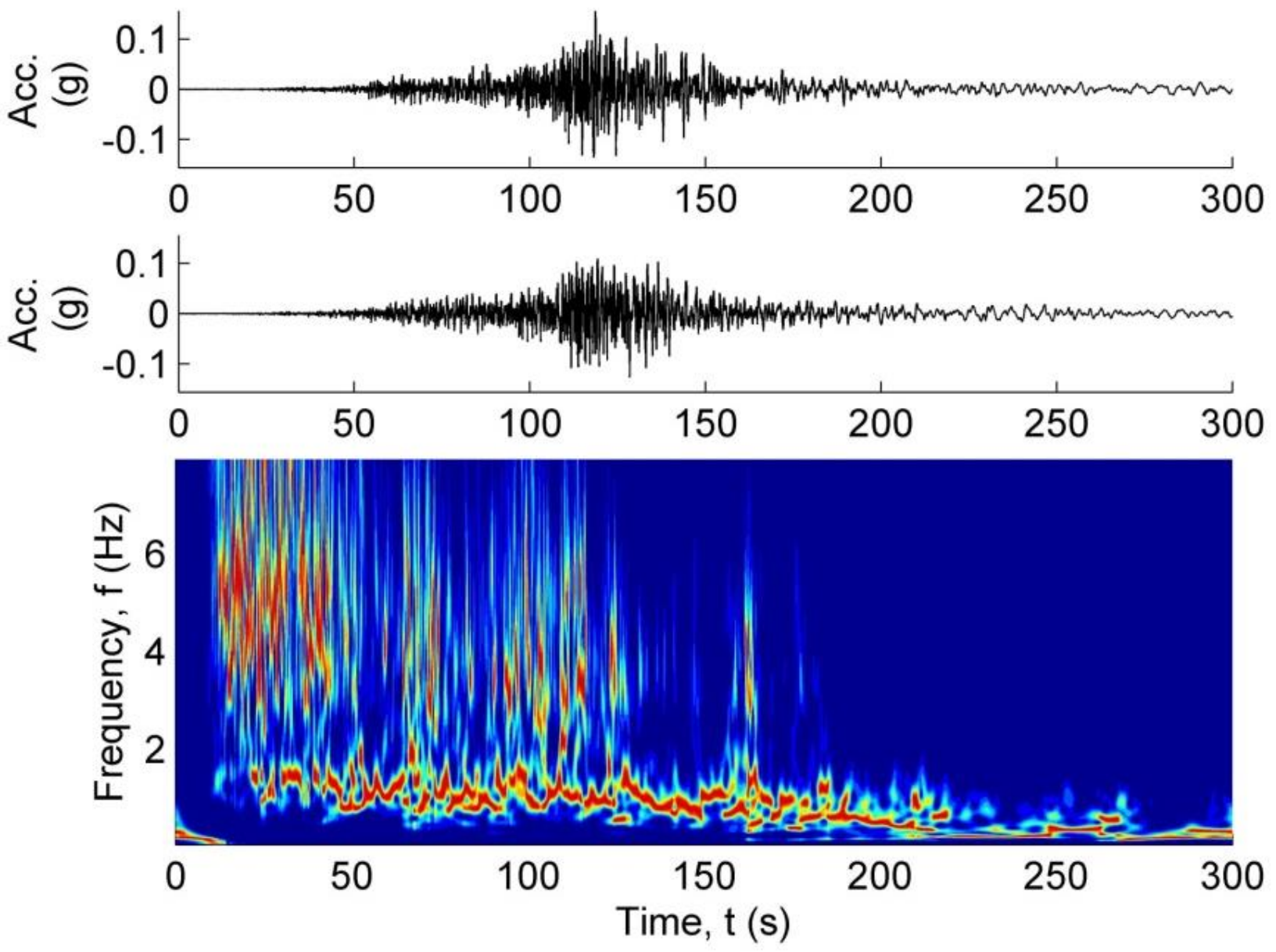

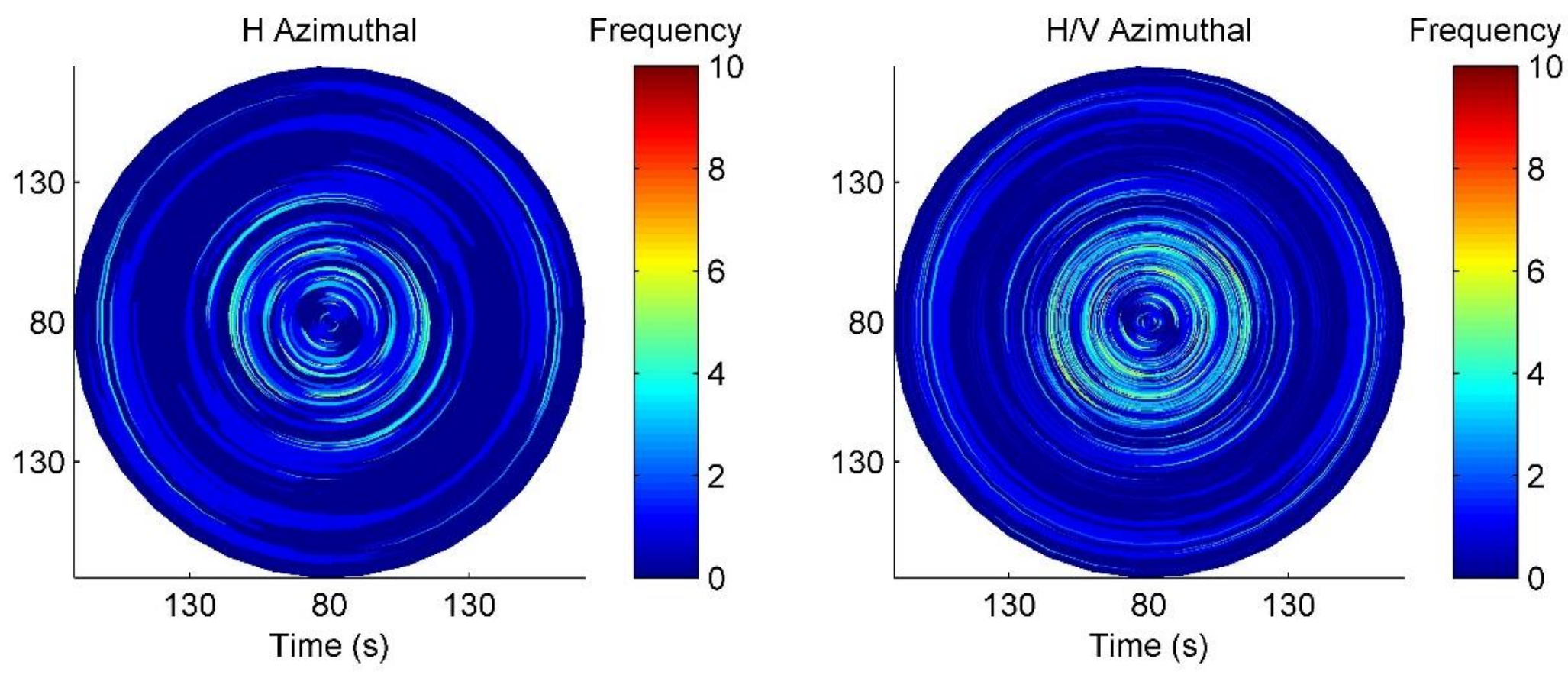


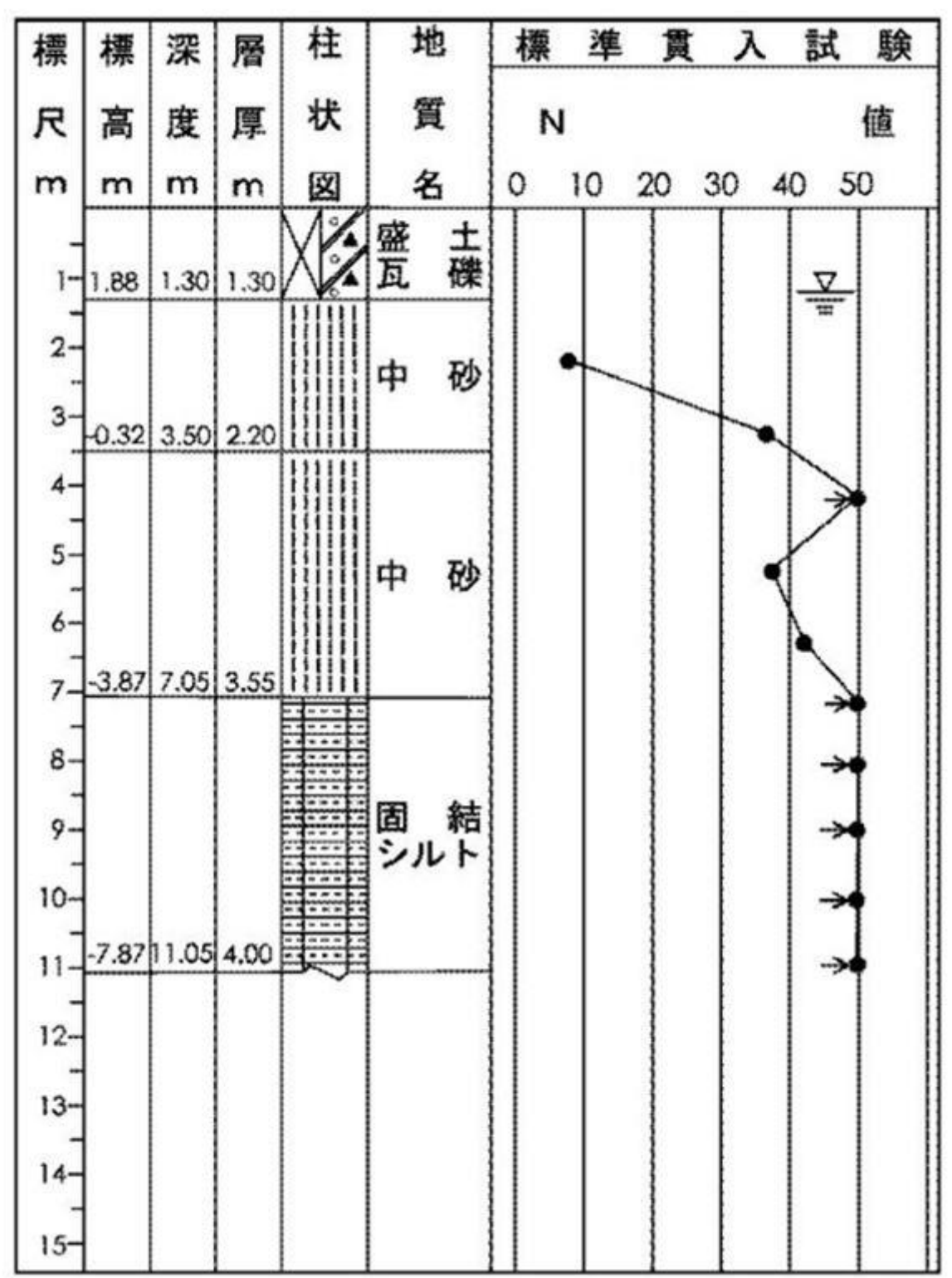



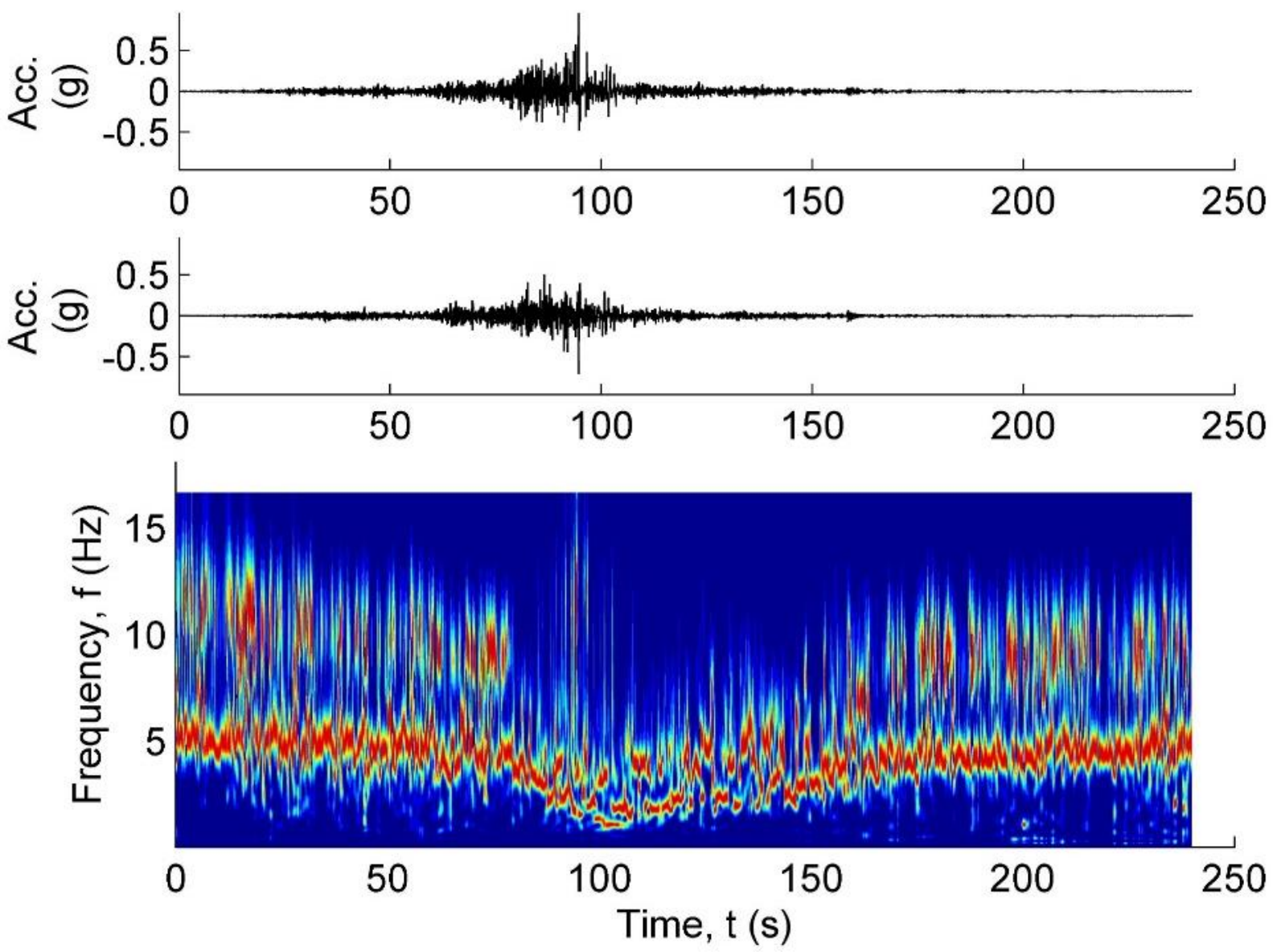


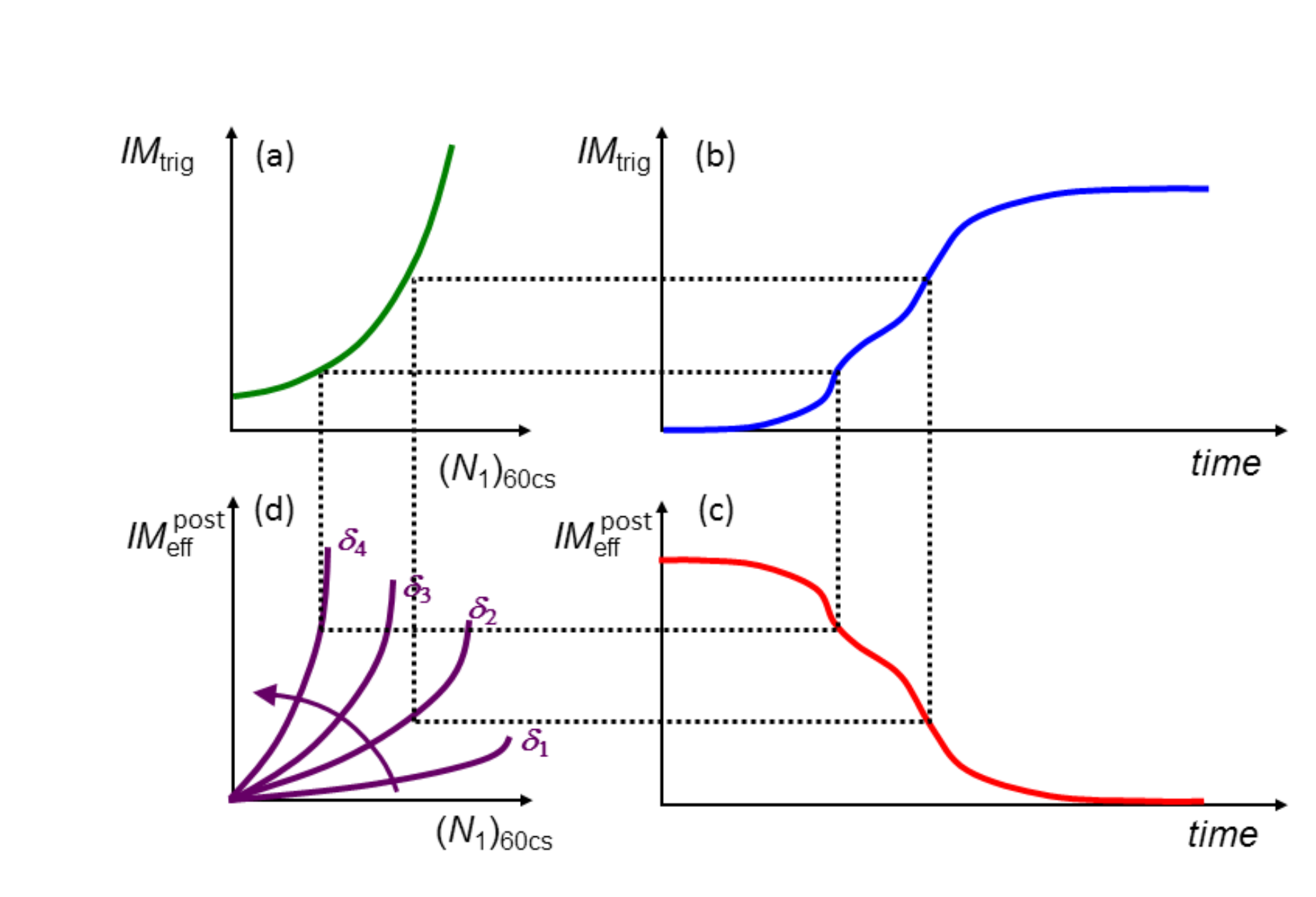

.
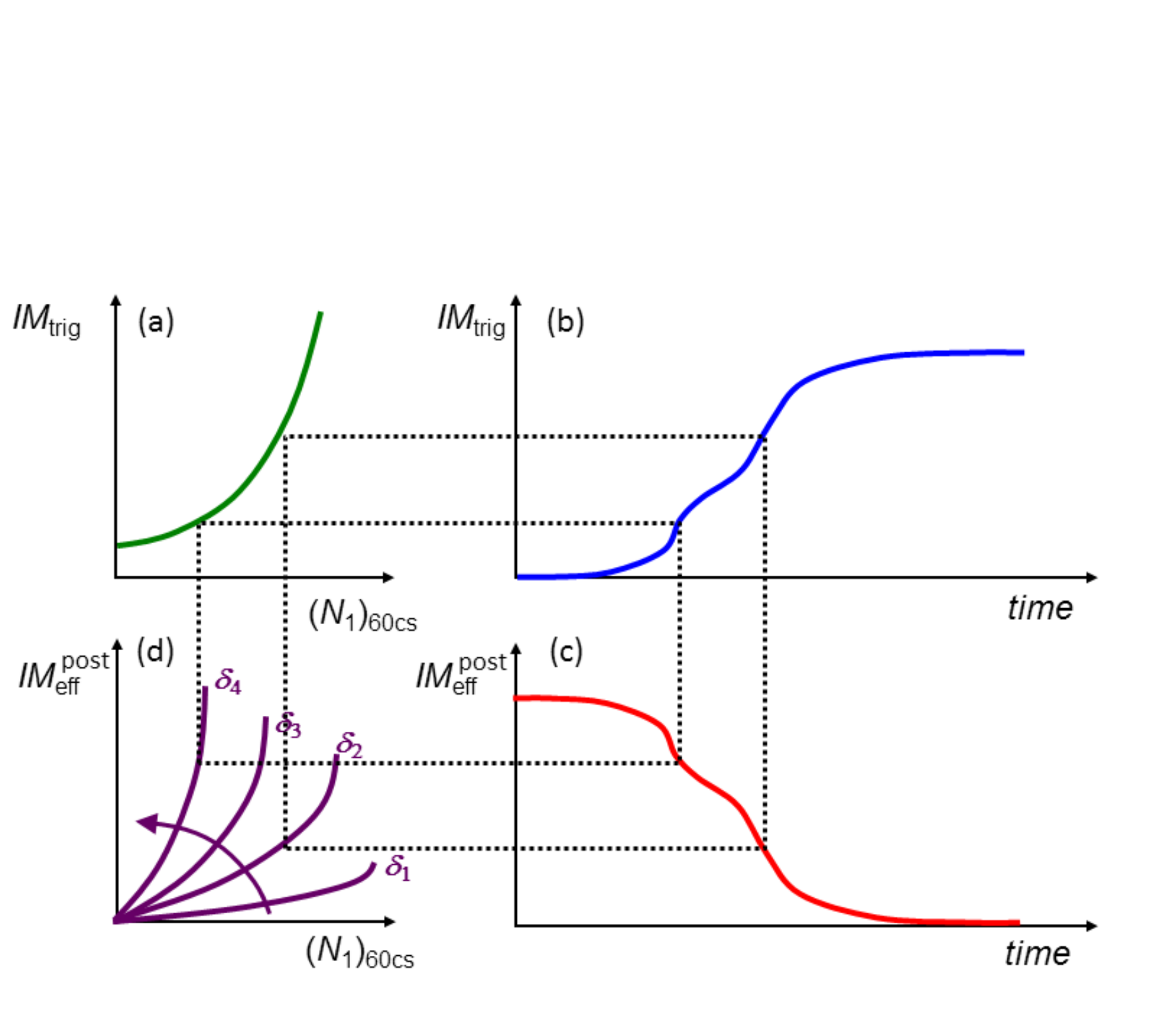


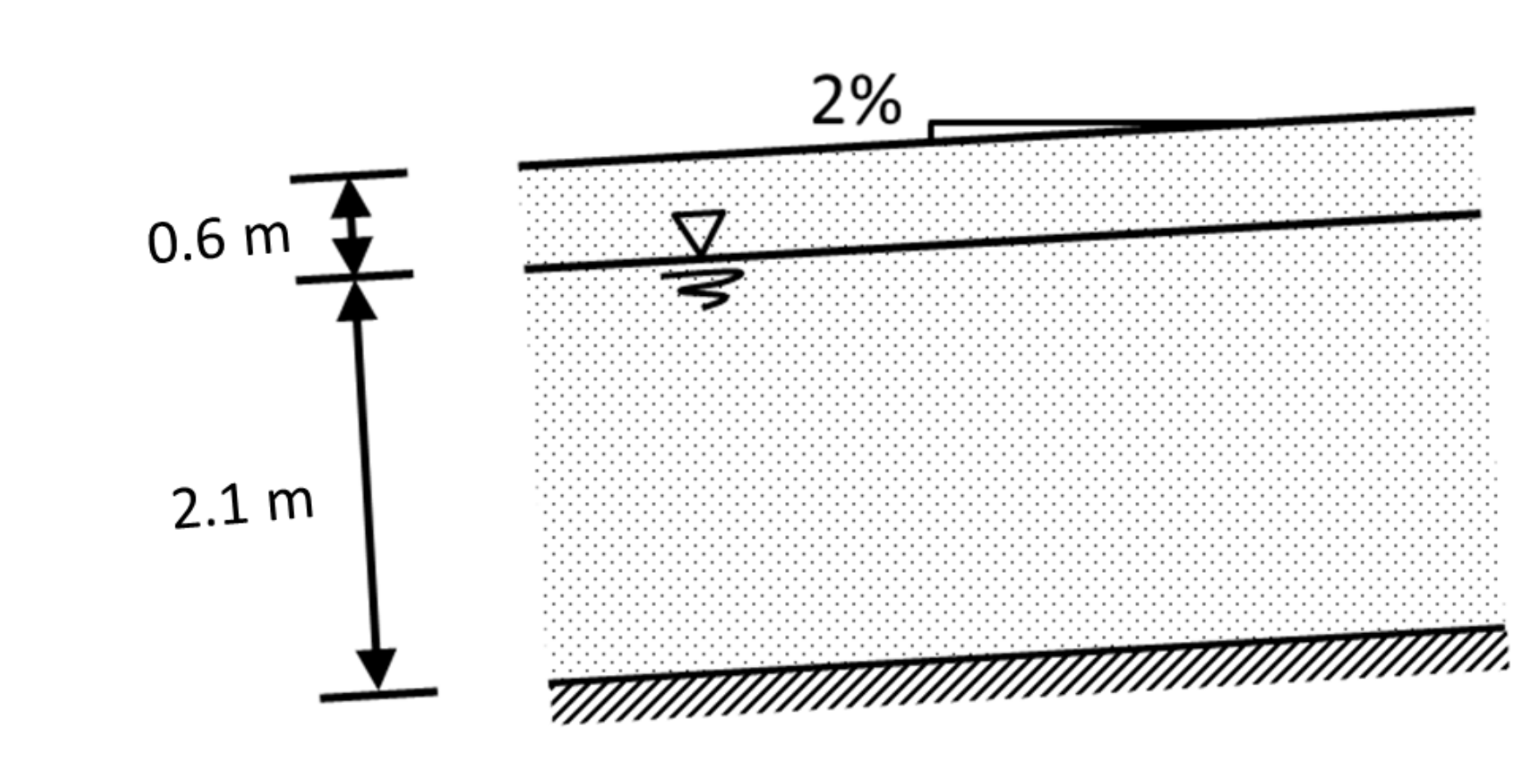

Figure

\section{Figure}

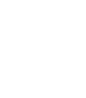

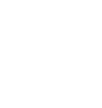

.

.
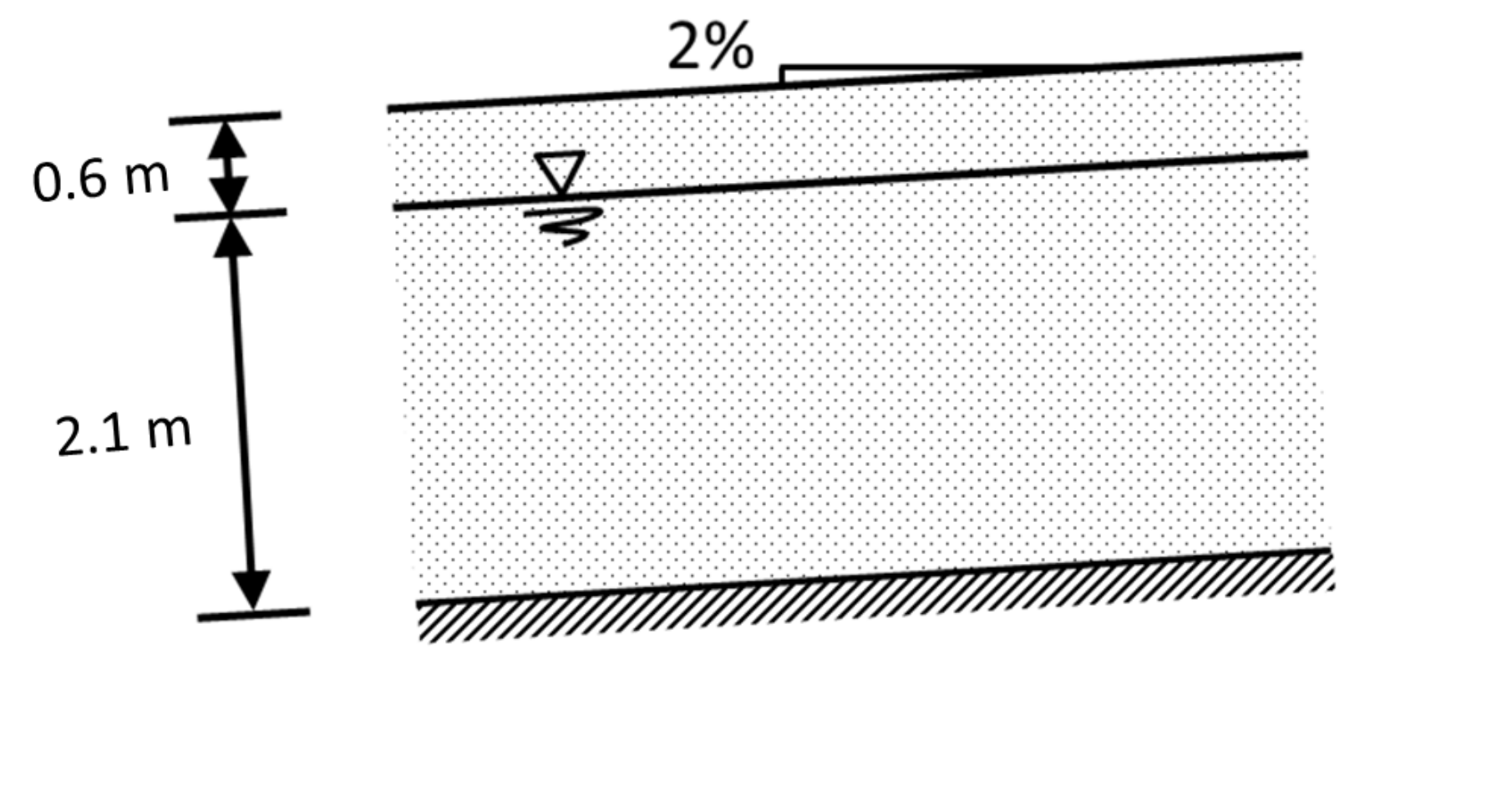


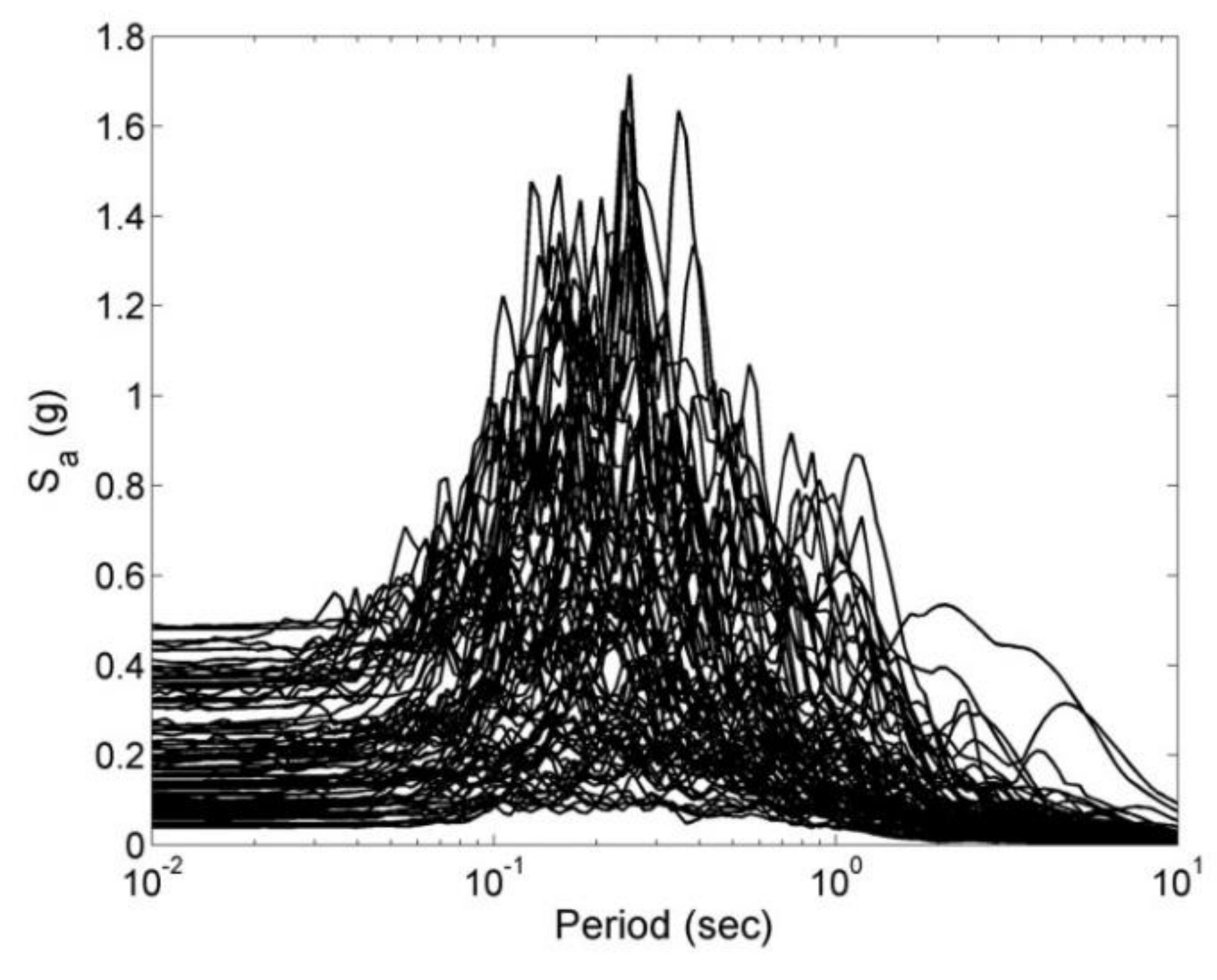

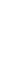




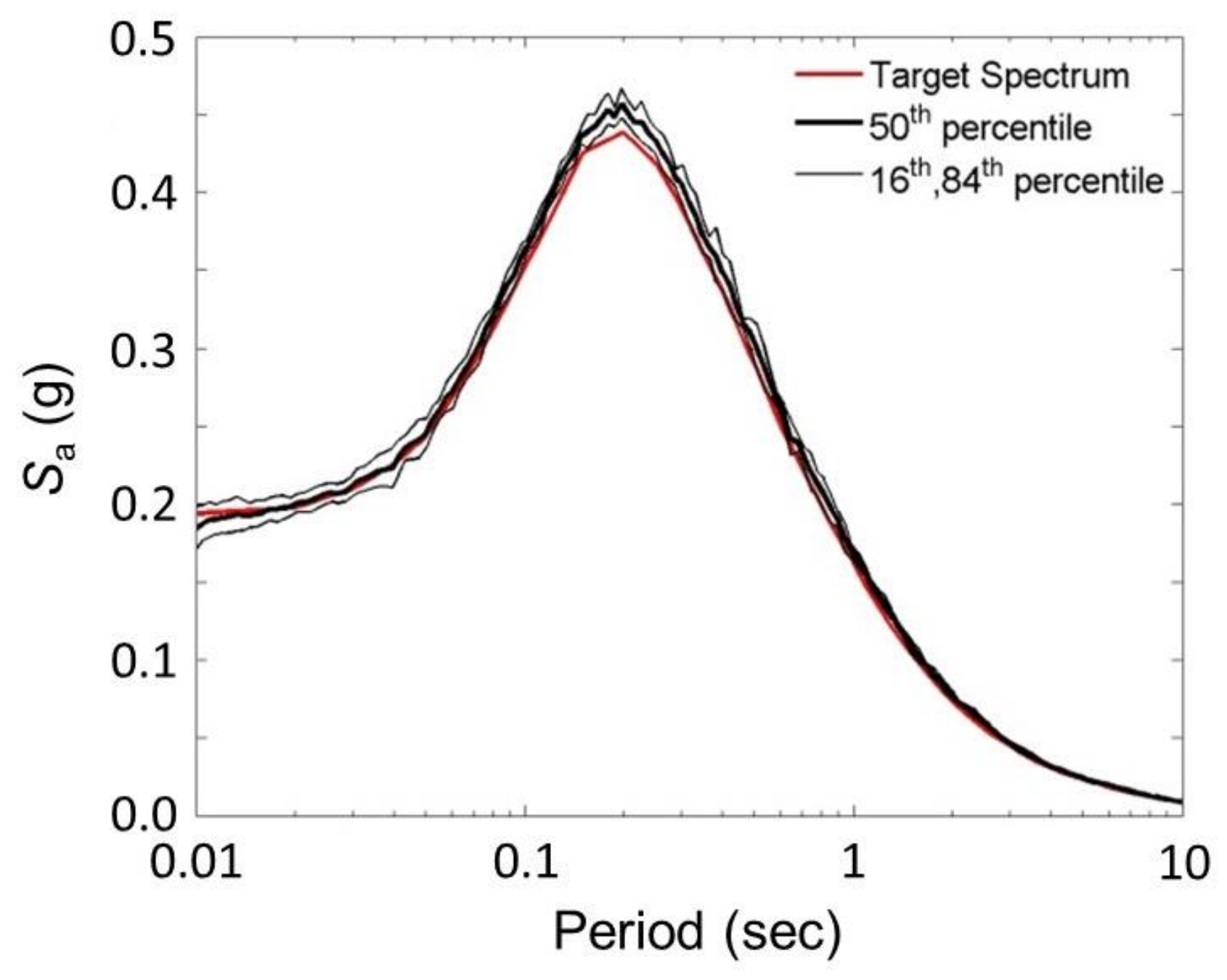




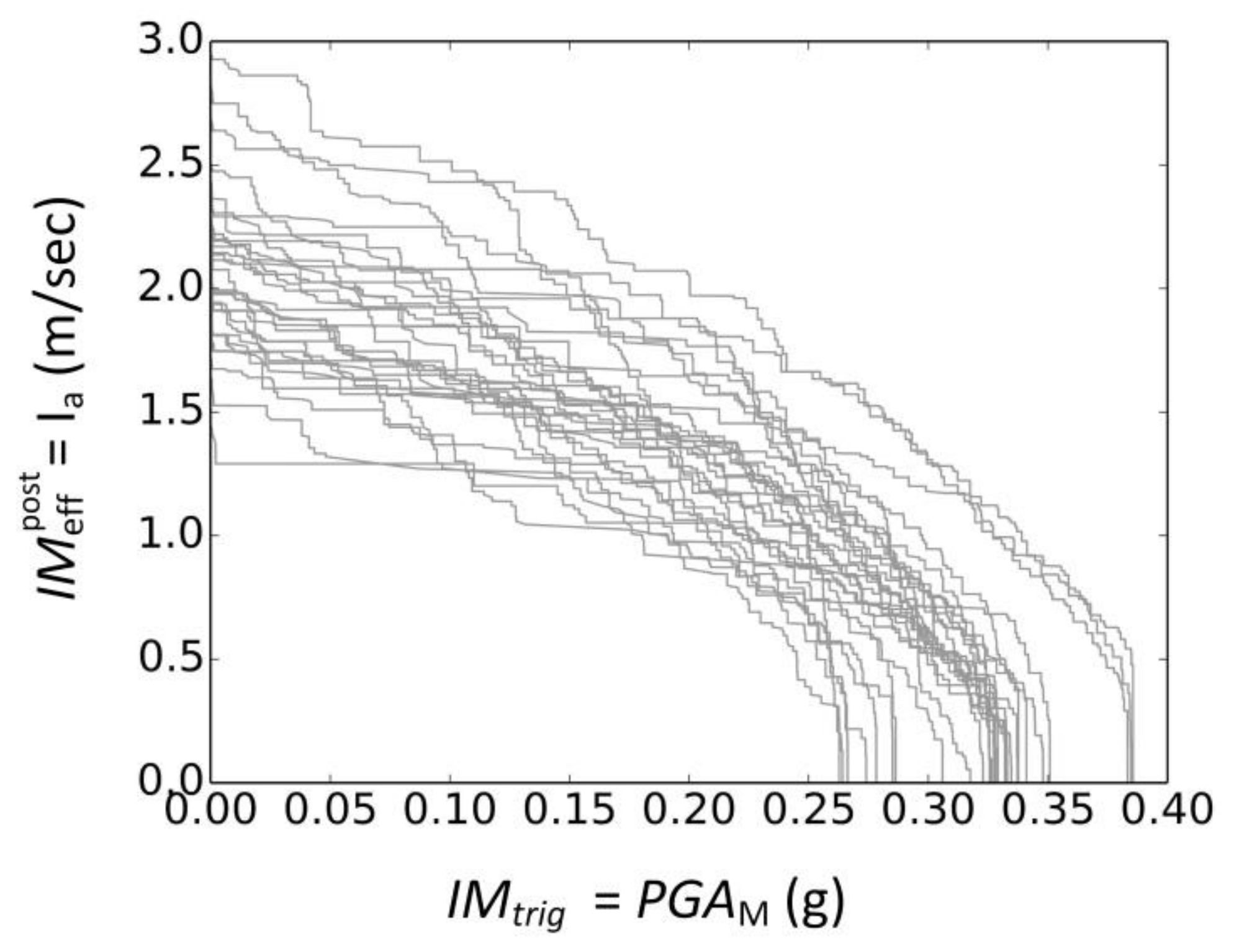

$$
I M_{\text {trig }}=P G A_{M}(\mathrm{~g})
$$



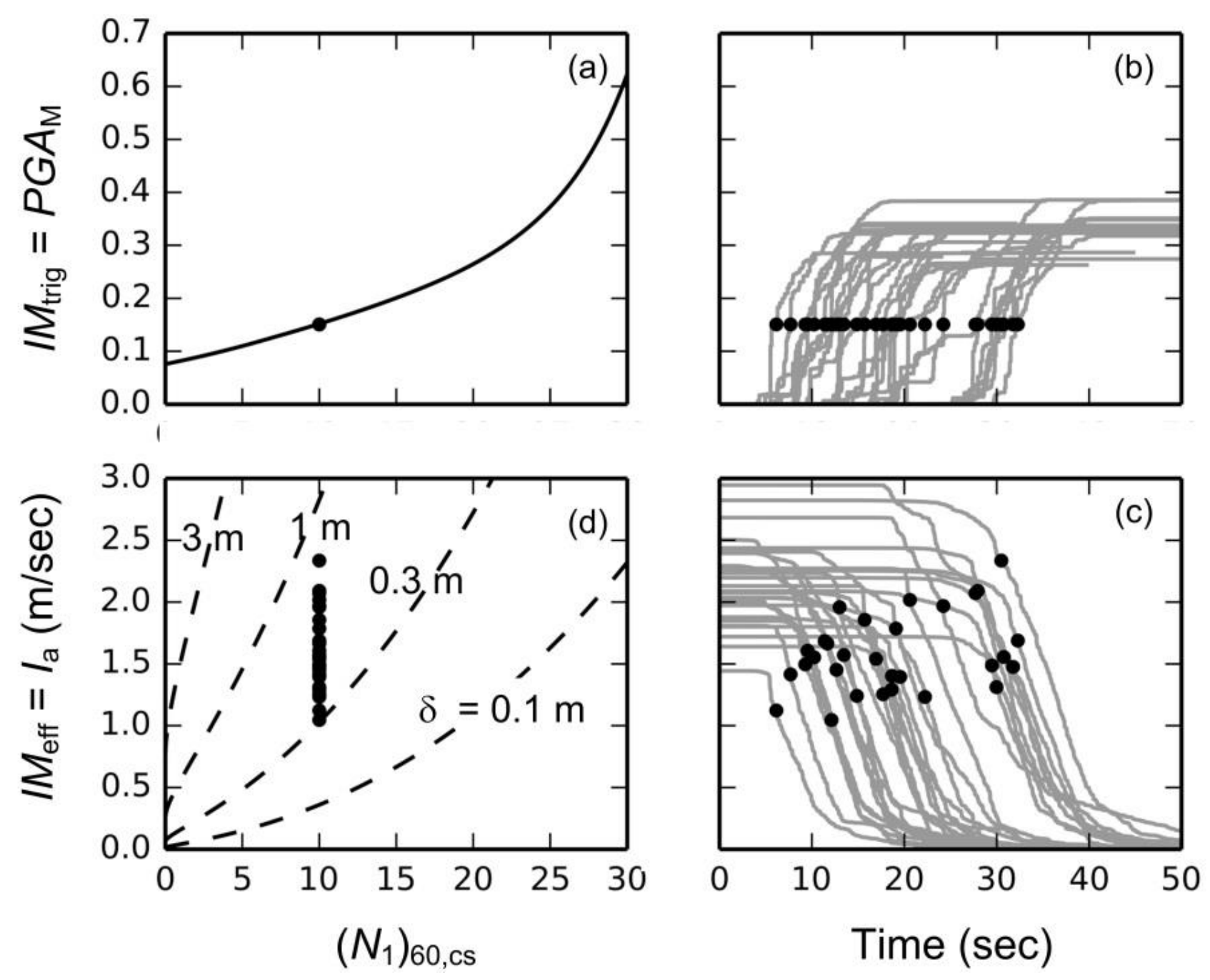

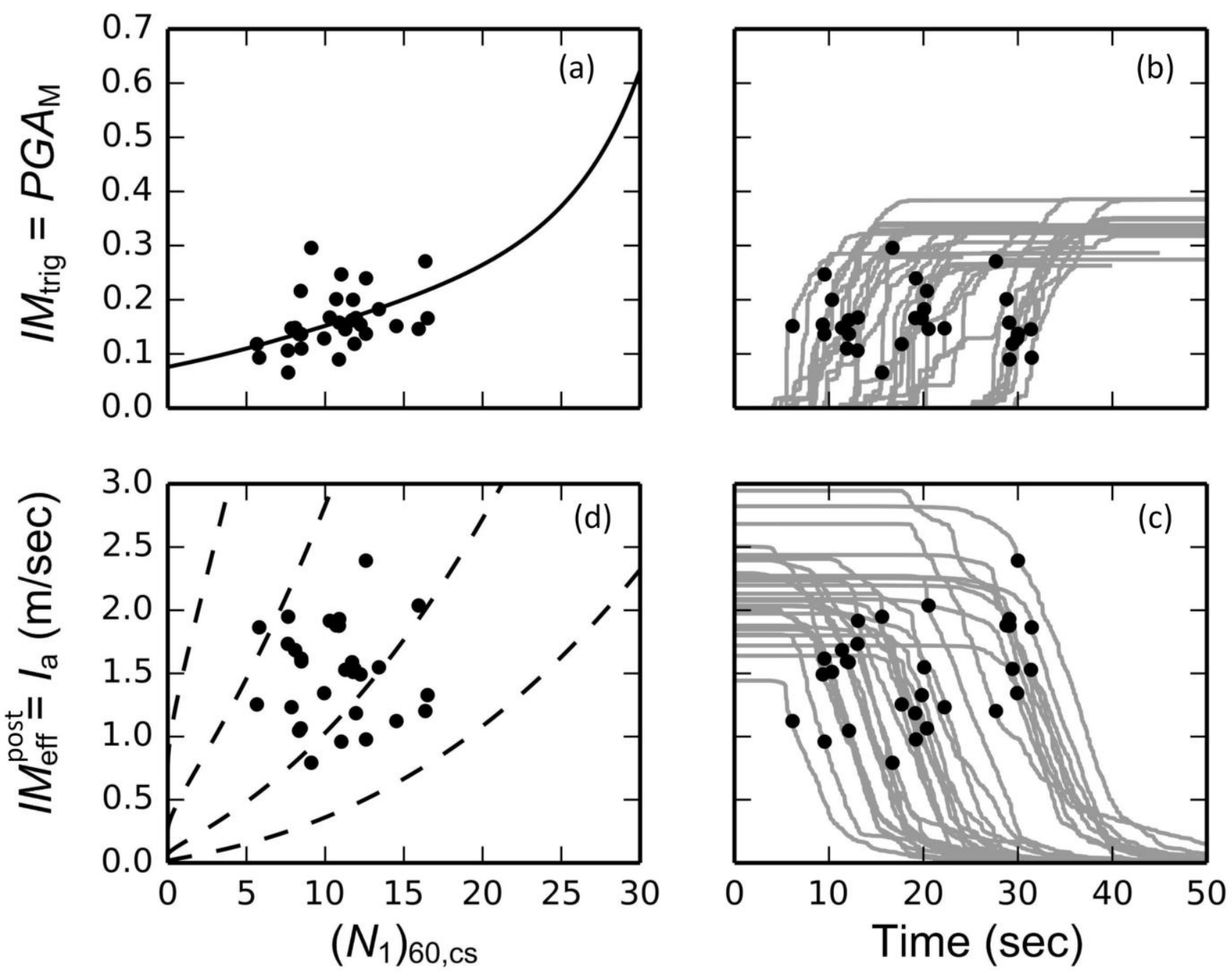

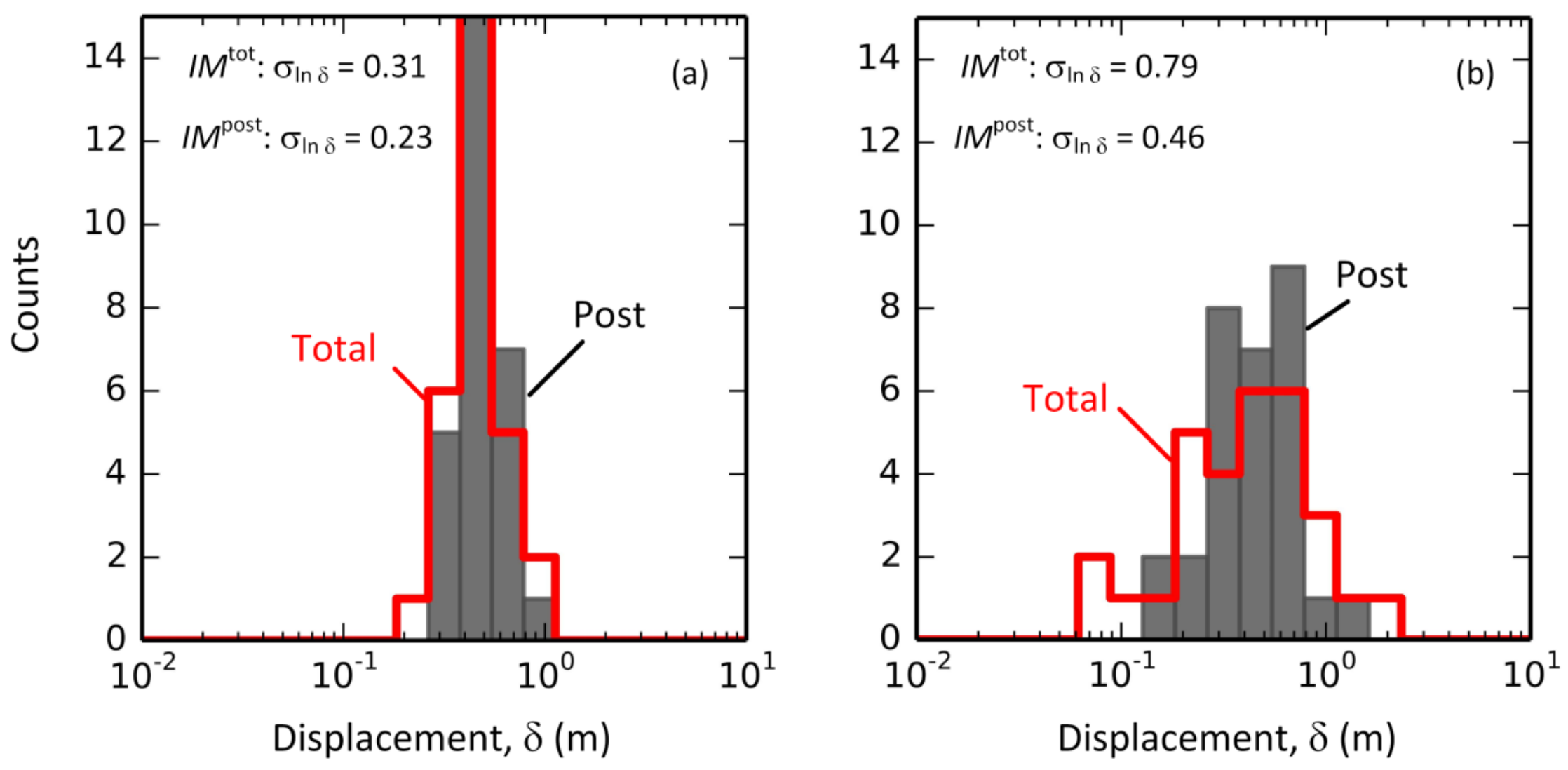